
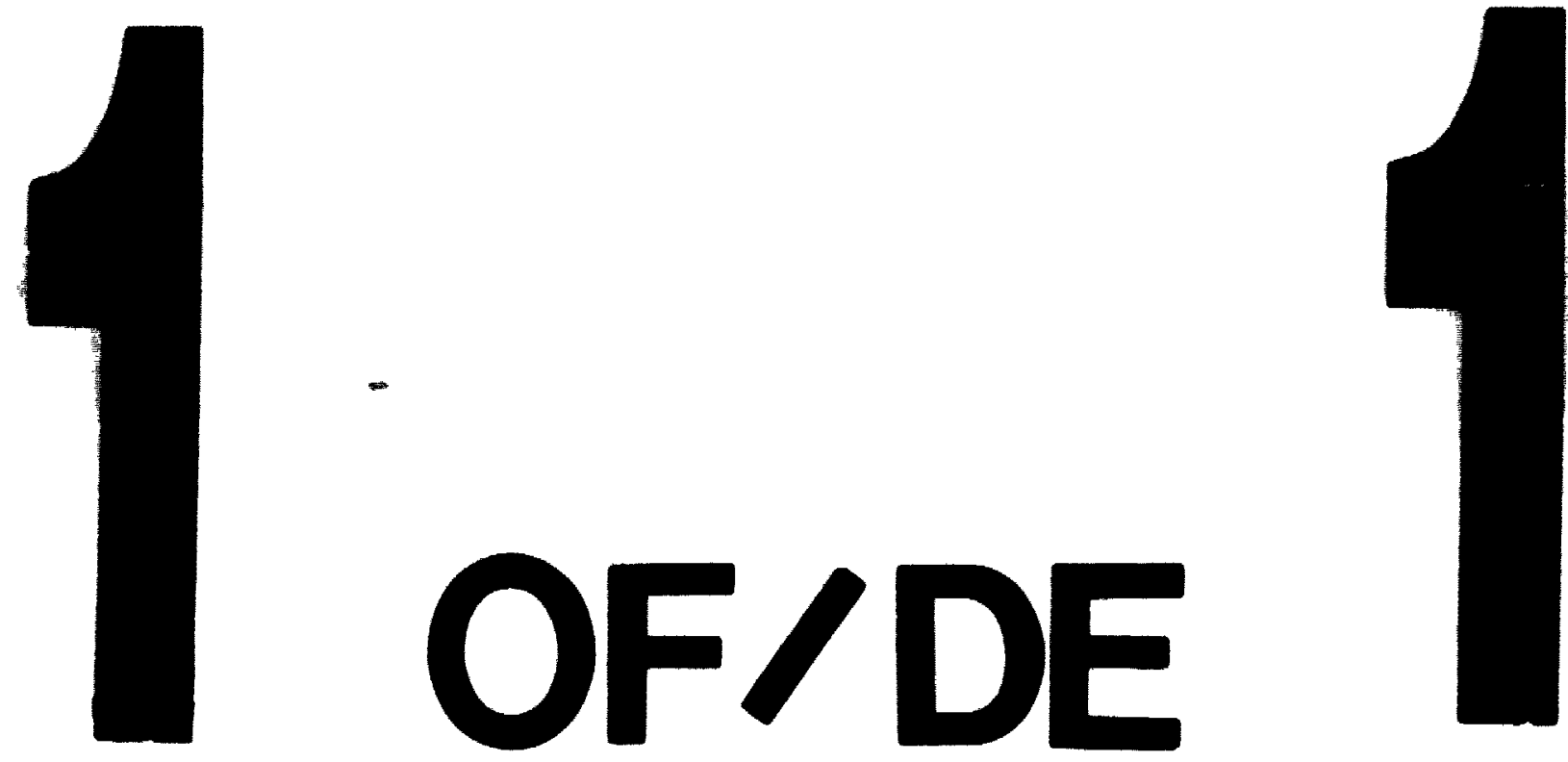

PM.13' ? 4 " PHOTOGRAPHIC MICAOCOPY TARGET NBS 10102 ANSI/ISO \#2 EOUIVALENT

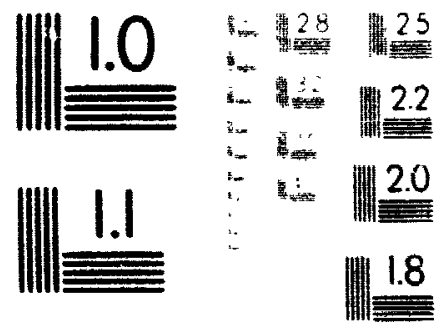

$$
\begin{aligned}
& \text { |||||||1.25 }
\end{aligned}
$$

PRECISIONSM RESOLUTION TARGETS 


\section{LAMINAR AND TOPOGRAPHICAL ANALYSIS OF PERIRHINAL CORTEX KINDLING IN THE RAT}

by

\section{LeANNe felstead, B.A. Honours}

A thesis submitted to the Faculty of Graduate Studies and Research in partial fulfillment of the requirements for the degree of Master of Science

Department of Psychology

Carleton University

Ottawa, Ontario

Canada

September 10, 1996

(1) copyright

1996. Leanne Felstead 
National L:torary

of Canada

Acquisitions arid

Bitblograptic Services Branch

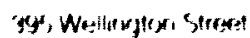

inawas opharict

MIAIN4
Biblrotheque nationale

du Canada

Direction des acquisitions el

des services bibliographiques

395 rue Wellingtor

(Otawa (Ortark)]
The author has granted an irrevocable non-exclusive licence allowing the National Library of Canada to reproduce, loan, distribute of sell copies of his/her thesis by any means and in any form or format, making this thesis available to interested persons.

The author retains ownership of the copyright in his/her thesis. Neither the thesis nor substantial extracts from it may be printed or otherwise reproduced without his/her permission.
L'auteur a accordé une licence irrévocable et non exclusive permettant à la Bibliothèque nationale du Canada de reproduire, prêter, distribuer ou vendre des copies de sa thèse de quelque manière et sous quelque forme que ce soit pour mettre des exemplaires de cette thèse à la disposition des personnes intéressées.

L'auteur conserve la propriété du droit d'auteur qui protège sa thèse. Ni la thèse ni des extraits substantiels de celle-ci ne doivent être imprimés ou autrement reproduits sans son autorisation.

ISBN $\quad 0-612-19538-4$ 
Nom L Leanne feistea d

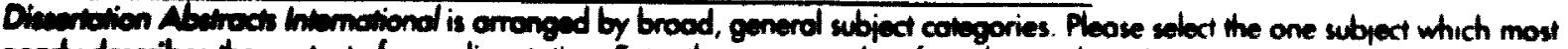
manty decribes the coniment of your discurtation Enter the corresponding four-digit code in the spoces provided

Scuincis sunct ram

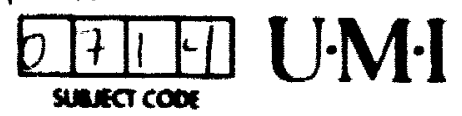

sturect cob

\section{Sulind Congovios}

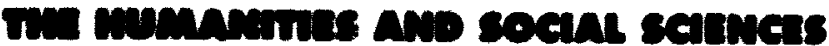

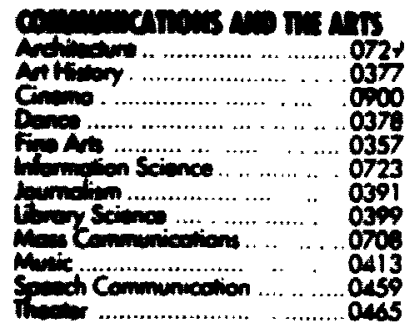

\section{Enim}

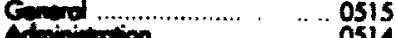

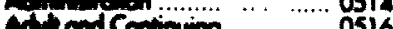

A.

Af

Atimed and Minicinind ........0282

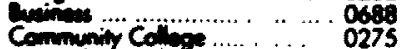

Cirriculum and hisuction 0727

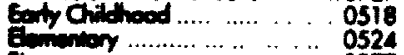

Fince .................. . . 027

Guidene and Counding . 0519

Hoin ................ . . $\mathbf{0 6 8 0}$

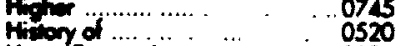

Hene Eeonemies. . 0278

himtial ............. .. .0521

Monomance. ... . . . . . 0230

Mutic .......... . 0522

Finsod . ... ....
Fimosechi, aeveiow an

nescosich

Philosephy

Relowon

Aticel Sndies

Clergy

Filosophy of

Theology

cenclstant

Amoricon Sudies

Antropelogy.

Cilund

Pimpeed

Qusiness Administrotion

General

Accovinting

Conking

Monogerment

Conotion Sidies

Econgmics

Agricuthrol

Commerce Business

Finonce

History

Lobor

Follore

Geogrophy

History

Generd

\section{Tri genancis and anomuanue}

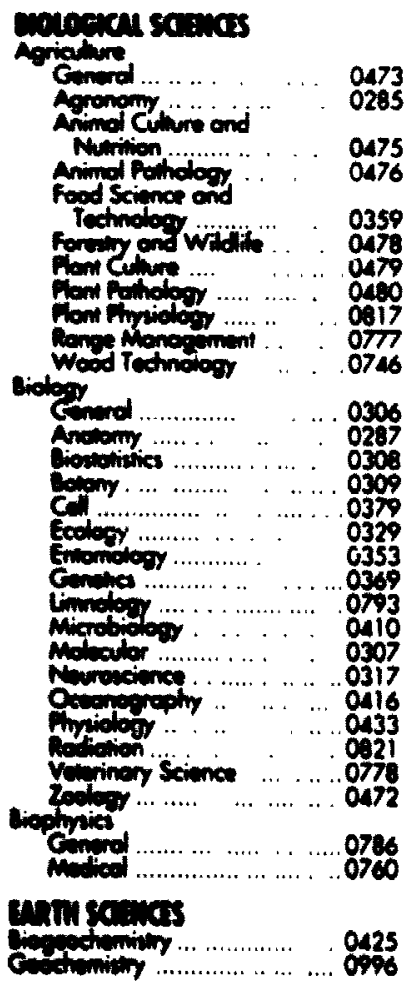

Goodesy

Gology

Gopplasics

Mnneralogy

Polecobolony

Poloomology

polpozoology

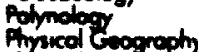

Phyicel Oevonogrophy

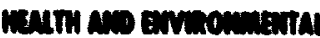

scainas

Hedith Seinater

Gonerol

Audiology

Eontuction

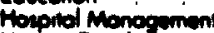

tumon Demlopment

mominowigy

Madicine ond Surgery

Muned thodin

Nurung

Obremes and Grpecelogy 0380

Oetupotionol theith and

Ophropy....

Potholeogy

Prormecologis

Promery

Ariced th

nocrovition

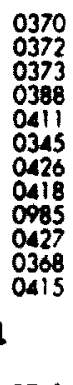

.0768

0566

0300

0567

0350

0769

0758

0564

0347

0570

0380

0351
0381
0571

o571

o572

037

0573

0573
Enmponmentel Sciencts

Chementurepy

Nelic Hoim

\section{Speech Pothology}

Home Econgy

\section{Mrsical satwas}

Pure Sciences

Chemisity

Agricuthro

Anricutural

Broctiomisty

Inorgonic

Nuchor.

Frormocentical

Phycol

Potymer

Radiotion

Molvemotics

Prysics

Generd

Acoushes

Astronomy and

Astrophyixs:

Amospheric Science

Electroness ond Electrictity Elementery Porticles ond

Fing End proy

Flud ond Plos

Molnculor

Nucios

Rediction

Sand Stow

Shomsthes

Anrind Sciunces

Aplined Mechones

Compuner serence

0427
0318
0321
0319
0320
0322
0469

0323

032

0320
$032 ?$

0310

0310
0272
0770

0454

0338
0385

0501

0503
0505
0508

0508

$050 \%$

051

0358

0360

0578

\begin{tabular}{|c|c|}
\hline 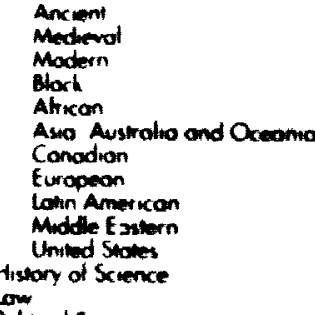 & $\begin{array}{l}0581 \\
0582 \\
0328 \\
0331 \\
0332 \\
0334 \\
0335 \\
0334 \\
0333 \\
033 \\
0585 \\
0308\end{array}$ \\
\hline Allow and & $\begin{array}{l}0615 \\
0616 \\
0617 \\
0814 \\
0452\end{array}$ \\
\hline $\begin{array}{l}\text { logy and Penalogy } \\
\text { ophy } \\
\text { nd Rocuol Studies } \\
\text { oi and fomily }\end{array}$ & $\begin{array}{l}0626 \\
0627 \\
0938 \\
0631\end{array}$ \\
\hline $\begin{array}{l}\text { ind laboor } \\
\text { Sociol Wellore } \\
\text { chure and }\end{array}$ & $\begin{array}{l}0620 \\
0630\end{array}$ \\
\hline $\begin{array}{l}\text { Methods } \\
\text { Monol Plonning } \\
\text { es }\end{array}$ & 09 \\
\hline
\end{tabular}

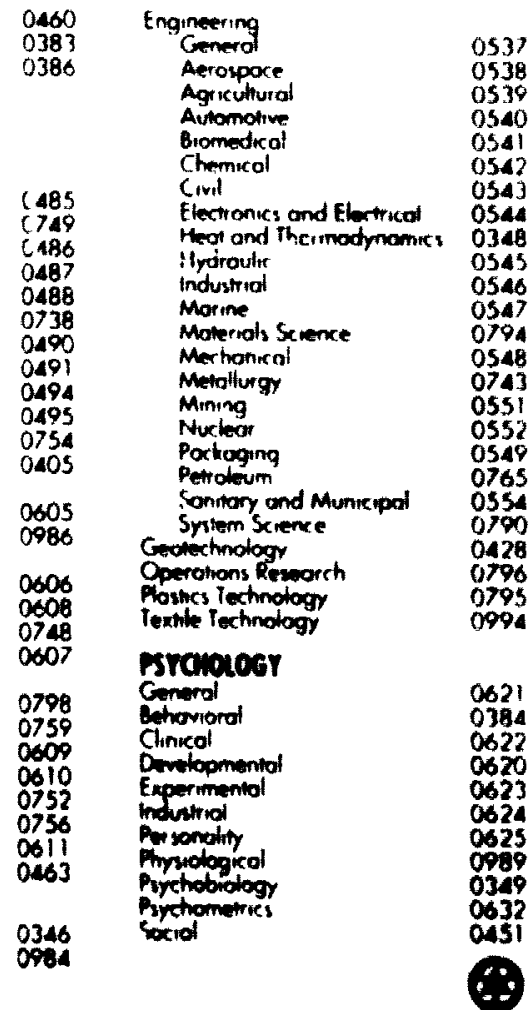


The undersigned hereby recommend to the

Faculty of Graduate Studies and Research acceptance of the thesis,

\title{
Laminar and Topographical Analysis of Perirhinal Cortex Kindling in the Rat
}

\author{
submitted by
}

Leanne Felstead. B.A Honours

in partial fulfilment of the requirements for the degree of

Master of Science

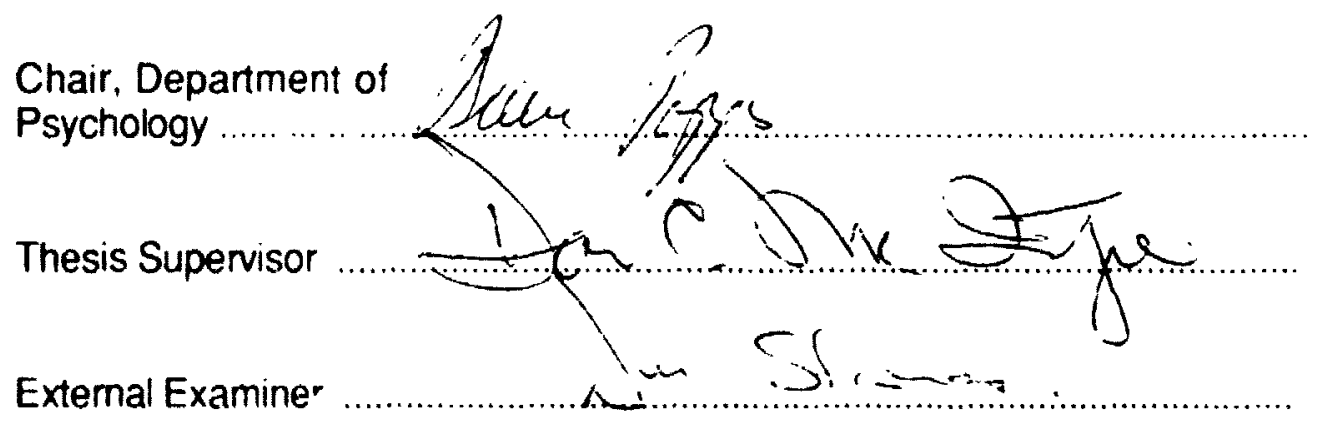

Department of Psychology

Carleton University

Ottawa, Ontario

Canada 


\begin{abstract}
The objective of this thesis was to advance our understanding of perirhinal cortex involvement in limbic convulsive seizures. Compared to other forebrain structures, the perirhinal cortex was previously shown to be highly excitable in both the slice preparation and in the intact animal. We felt that the fast kindling rates and short latencies to the onset of forelimb clonus found in the anterior perirhinal cortex warranted further in vivo investigation of this cortex in its entirety. Compared to other perirhinal areas, we found the deep layers of the most rostral region to demonstrate the greatest sensitivity to daily stimulation. The ability of this area to respond with an after-discharge (AD) and stimulus bound (SB) behavior at low thresholds and to rapidly access mechanisms involved in sustained generalized convulsions suggested that the anterior perirhinal cortex may be most critically involved in epileptogenicity. The implication of these findings are discussed in relation to the hypothesis that discharge triggered during kindling from limbic sites commonly recruits the perirhinal cortex as an intermediate structure to establish susiained generalized convulsions.
\end{abstract}


Dedicated to my brother Kerry 


\section{Acknowledgements}

I would like to thank my supervisor Dr. Dan Mcintyre for his encouragement and guidance throughout my Masters degree. The enthusiasm and support shown by him provided a very positive graduate traınıng experience for me. I will always admire his hard work and complete dedication to the study of epilepsy.

I wish to acknowledge and thank Mary Ellen Kelly (for teaching me lab techniques), Glenda McNeil (for help with my results), Jenny Grabowski. Wayne McLeod, and Yves Bureau who were all so much more to me than lab partners These friends gave me a very happy home away from home

To my parents, Marion and Barry Felstead, I hope that someday I can give to them all that they have given me. I truly believe that they are the strength behind all of my achievements. Thank you

Finally I would like to recognize the love and support of my best friend. Robert Sullivan, and thank him for believing in me. 
TABLE OF CONTENTS

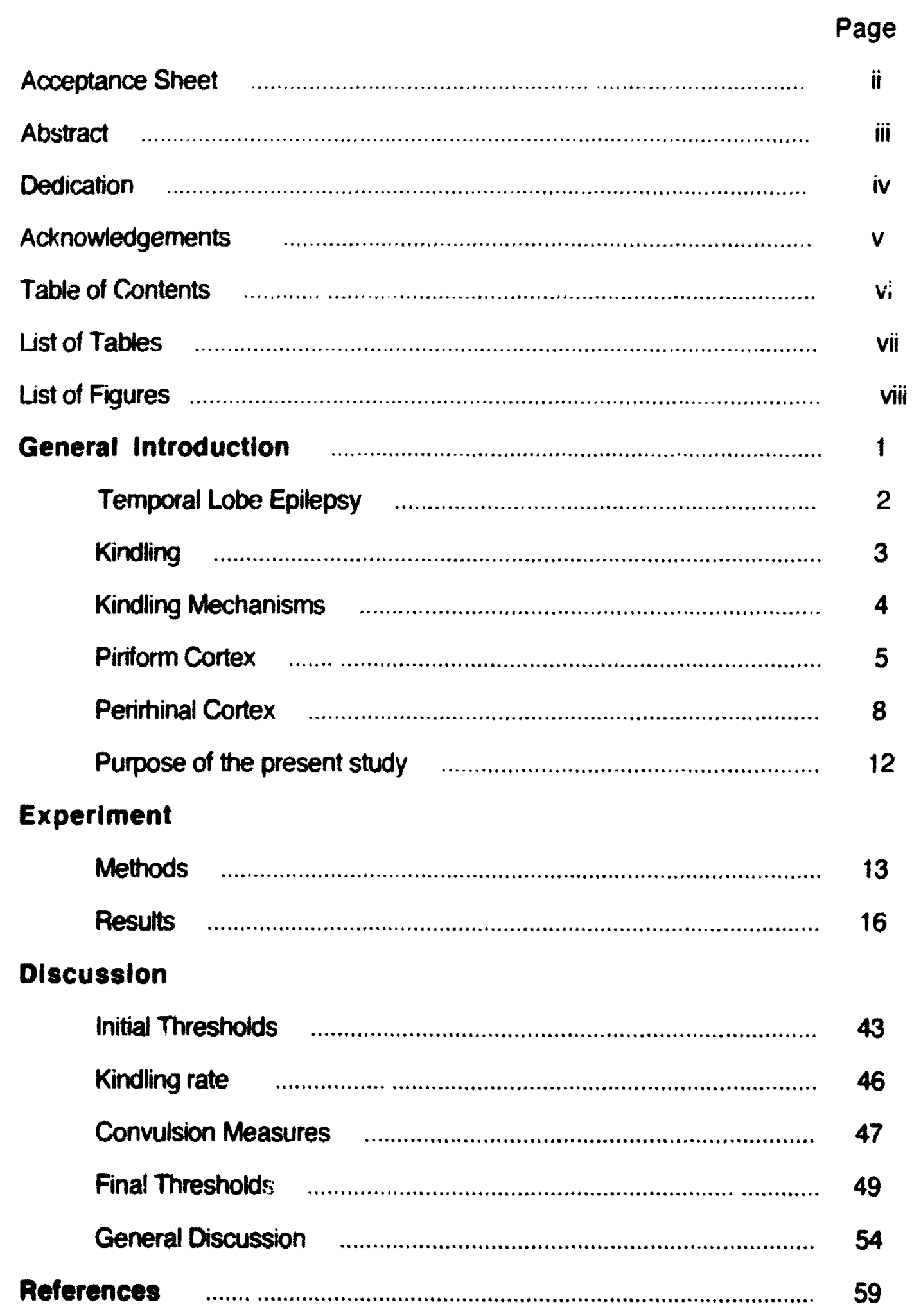


TABLE

1

2

\section{DESCRIPTION}

The Mean ( \pm S.E.M.) initial and final after-discharge (AD) and stimulus bound (SB) threshold in $\mu \mathrm{A}$ in 4 groups cf rats, each kindled from 1 of 4 different anterior to posterior locations in the perirhinal (PRh) cortex (see method).

The mean ( \pm S.E.M.) initial and final after-discharge (AD) and stimulus bound (SB) thresholds in $\mu \mathrm{A}$ in rats kindled from either superficial or deep perirhinal (PRh) cortex locations.
PAGE 


\section{LIST OF FIGURES}

FIGURE 1. Schematic diagram taken from Swanson (19??) showing the electrode tip location of each rat of the 4 perirhinal cortex kindled groups.

FIGURE 2. Mean ( \pm S.E.M.) kindling rate to the first stage- 5 convulsion for all 8 perirhinal (PRh) subgroups.

FIGURE 3. Mean ( $t$ S.E.M.) latency to forelimb clonus of the 6 stage-5 convulsions for all 8 perirhinal (PRh) subgroups.

FIGURE 4. Mean ( \pm S.E.M.) convulsion duration (duration of forelimb clonus) of the 6 stage -5 convulsions for the 4 topographical perirhinal (PRh) groups.

FIGURE 5. Mean ( \pm S.E.M.) after-discharge (AD) duration of the 6 stage-5 convulsions for the 4 topographical perirhinal (PRh) groups.

FIGURE 6. Mean ( \pm S.E.M.) initial and final threshold at which an afterdischarge (AD) was produced for the 4 topographical perirhinal (PRh) groups.

FIGURE 7. Mean ( \pm S.E.M.) initial and final threshold at which an afterdischarge (AD) was produced for the 2 laminar perirhinal (PRh) groups.

FIGURE 8. Mean ( \pm S.E.M.) initial and final threshold at which stimulus bound (SB) motor behaviors were produced for the 4 topographical perirhinal (PRh) groups.

FIGURE 9. Mean ( \pm S.E.M.) initial and final threshold at which stimulus bound (SB) motor behaviors are produced for the 2 laminar perirhinal (PRh) groups. 


\section{General Introduction}

Epilepsy is a chronic neurological disorder characterized by recurrent periods of abnormal synchronous neuronal discharges in either focal or widespread pathways of the brain (Gastaut, 1973). There are serious behavioural consequences that underlie this abnormal neuronal activity. which range from involuntary contractions of striated muscles to massive convulsions and loss of consciousness. Although a person may experience at least one seizure event in their lifetime, the diagnosis of chronic epilepsy requires that a patient experience recurrent seizures. Epilepsy is one of the most common neurological diseases, afflicting approximately $1 \%$ of the American population (Hauser \& Kurland, 1975).

Over forty types of epilepsy have been classified within the broad categorization of either partial or generalized epilepsy (Beldhuis, 1993). The abnormal discharge of a partial seizure begins focally within one hemisphere of the brain whereas the onset of a generalized convulsion involves widespread synchronous discharge in both hemispheres of the brain. The type of convulsion that is experienced by a patient diagnosed with partial epilepsy is categorized further on the basis of whether consciousness is retained during the seizure. Patients may experience impaired consciousness during a complex partial seizure (CPS) but will remain aware during a simple partial seizure. Since the majority of CPSs begin in the temporal lobe, they are often referred to as temporal lobe seizures (Williamson et al., 1987). Over time, the focal synchronous discharge of partial seizures may grow, recruiting areas of the brain necessary for seizure generalization. This type of seizure is classified as a partial seizure with secondary generalization. Although the most severe neurological and behavioural consequences occur when a seizure is 
generalized from the onset, it is most often patients suffering from complex

partial seizures that are afflicted with intractable epilepsy (French et al., 1993).

If adequate control of seizures is not attained through pharmacological treatme $t$, patients may have to undergo surgical therapy.

\section{Temporal Lobe Epilepsy}

It has been suggested that temporal lobe structures such as the hippocampus (Babb \& Brown, 1987) or the amygdala (Gloor, 1992) may be the initiation sites of abnormal epileptic discharge involved in temporal lobe epilepsy. Without a complete understanding of the neural circuitry and the key structures that may be involved in initiating and/or sustaining the epileptic event, the areas of the brain to be surgically excised in hopes to eliminate the temporal lobe seizures is very controversial. A degree of surgical control over CPSs has been demonstrated in patients that have undergone resection of the anterior hippccampus and/or entorhinal cortex (Goidring et al., 1992). Conversely, others report that removal of the amygdala and only a small portion of the hippocampus ameliorate the same type of seizures (Feindel \& Rasmussen, 1991). Still others feel that extensive resection of both the amygdala and the hippocampus is necessary to successfully control CPSs (Awad et al., 1989; Nayel et al., 1991; Spencer et al., 1984). The diverse surgical strategies used to control temporal lobe epilepsy illustrates the need for a unified technique that will target the most critical structure(s) involved. Clearly, the information that is presently available to surgeons performing these excisions is not yet sufficient to derive a standard surgical protocol specifying the anatomical area and extent of these resections. Until the mechanisms involved in the genesis of temporal lobe epilepsy is more clearly understood, patients undergoing this kind of surgical therapy may suffer unnecessary excision of brain tissue to elude the 
epileptogenesis. Since poor experimental control and manipulation in the human epileptic population restricts researchers in their study of temporal lobe seizure networks, many animal models of epilepsy have been developed to advanced our knowledge in this area.

\section{Kindling}

The discovery that repeated daily stimulation to the saine brain structure results in a progressive increase in both electrophysiological atterdischarge $(A D)$ and self-sustained convulsive behaviour has provided an important animal model of epilepsy called kindling (Goddard et al., 1969). Until the discovery of the kindling phenomen $n$, most of the animal models for partial epilepsy involved the direct application of chemoconvulsants or certain metals into or onto the brain. The predictable nature of seizure development that occurs during the kindling process gives it an advantage over these other experimental models of partial epilepsy. Furthermore, kindling yields greater control over the induction of seizure activity and it avoids the problems inherent in chemical manipulations that may confound the experiment. Such confounds include pathology that may occur at the site of chemoconvulsant or metal injections/application, as well as the possible contamination of biochemical analysis due to the presence of exogenous agents.

The human form of epilepsy modeled by kindling is complex partial seizures with secondary generalization, which is characterized by abnormal discharge that begins in a restricted area of one hemisphere of the brain and then spreads to remote structures (Sato et al., 1990). The electrical stimulation that is delivered via a stimulating/recording electrode must be intense enough to elicit an afterdischarge for the generation and progression of kindling to occur (Goddard et al., 1969; Racine, 1972a). In the rat, five stages of convulsive 
behaviour development have been described (Racine, 1972a). The onset of observable convulsive behavior often involves stage 1 mouth and facial twitches that may quickly progress to stage 2 mastication and head nodding with additional stimulation. The appearance of forelimb clonus that is contralateral to the kindled site is described as stage 3 behavior. Stage 4 is classified as bilateral forelimb clonus with rearing. The rat has been fully kindled to a stage 5 generalized convulsion when bilateral forelimb clonus is accompanied by rearing and falling. There is a corresponding increase in the duration, complexity, frequency and amplitude of the electrographic discharge (afterdischarges) during this behavioral seizure development. Thus, a stepwise augmentation of both motor seizure and electrographic afterdischarge development is observed during the kindling process.

\section{KIndling Mechanisms}

Since limbic sites such as the amygdala or the hippocampus are unable to independently sustain clonic behavioural responses, their discharge must recruit structures with access to motcr substrates for a convulsion to generalize. The kindling-induced progressive increase in both the electrographic and behavioral seizure activity reflects the propensity of the focal synchronous discharge to recruit other brain areas. Structures recruited into the convulsive network during the kindling process display an inherent increase in excitability, independent of the kindled focus. The intrinsic alteration in functional excitability of remote sites is substantiated by a characteristic of kindling known as the transfer phenomenon (Goddard et al., 1969; McIntyre \& Goddard, 1973; Racine, 1972b). Positive transfer is a term used to describe enhanced seizure susceptibility of brain areas other than the kindled focus. Expressly, it takes fewer stimulations to provoke a kindled seizure in a limbic site if another limble 
site was previously kindled. A number of experiments were subsequently undertaken to ensure the enhanced responses of secondary sites to electrical stimulation did not simply reflect their ability to excite the originally kindled focus. Electrolytic lesions ablating a kindled site did not disrupt the transfer effect when kindling commenced in the secondary site (Goddard et al., 1969; Racine, 1972a). Similarly, split brain preparations that block communication between primary kindled sites and contralateral secondary sites did not modity the positive transfer that had occurred between the two structures (McCaughran et al., 1978; Mclntyre \& Edson, 1987). These findings demonstrate that the enhanced excitability of limbic structures recruited during the kindling process is independent of the activity in the kindled focus.

Some limbic sites possess an inherently greater sensitivity to the kindling process than others. A structure's kindling profile is based on the both the electrographic and behavioral seizure development that occurs from repeated stimulation of that site. The number of stimulations necessary to elicit a stage 5 convulsion (kindling rate) may give some insight into a structures ability to access motor substrates necessary to drive a convulsion.

\section{Pirlform Cortex}

Previously, of all the forebrain structures tested for kindling, the amygdala appeared to be the most sensitive to the kindling process, since generalized seizure development was achieved in the least number of stimulations (Goddard et al, 1969; Racine, 1972a). The piriform cortex was subsequently recognized to posses a profitis of kindling that reflected a greater sensitivity to the kindling process than that previously shown by the amygdala (Cain, 1977; Cain of al., 1988). As well as kindling faster than the amygdala, the piriform cortex demonstrates a number of other properties that has drawn interest to this 
area as an important structure in the limbic convulsive network (Mcintyre \& Racine, 1986).

Bursting cells found in the somatosensory cortex, piriform cortex, amygdala nuclei, endopirfiorm cortex, and the hippocampus (McCormick et al., 1985; Chagnac-Amitai et al., 1990; Rannie et al, 1993; Stewart \& Wong. 1993) have been associated with synchronized inythmicity (Silva et al. 1991) possibly involved in pathologies such as epilepsy (Hoffman \& Haberly, 1989; Burke \& Hablitz, 1994). Racine et al. (1986) proposed that the development of burst responses may represent an underlying kindling-induced alteration in cell function. Although the phenomenon of interictal splke development is poorty understood, their generation is believed to represent a bursting response within a population of neurons. Spontaneous interictal spikes were used to identify structures possibly involved in the generation of burst responses (Racine et al., 1986, 1988a). Racine et al. (1988a) discovered that the piriform cortex develops interictal spikes before other forebrain structures, independent of the kindled focus. The observation that the piriform cortex leads interictal spike development regardless of the limbic site kindled suggested that this area may be directly involved in the genesis of eplleptic discharges involved in the limbic convulsive network.

A model of status epilepticus (SE) that involves prolonged stimulation of a previously kindled amygdala, often generating extensive ipsilateral neuronal damage in the piriform cortex (McIntyre, Nathanson, \& Edson, 1982), further implicated involvernent of the piriform cortex in the generalization of limbic seizures. SE is a serious neurological disorder characterized by "a seizure or a serles of continuing seizures lasting more than $\mathbf{3 0}$ minutes without recovery between eplsodes" (Barry \& Hauser; 1993). The spontaneous offset of protracted seizures that occurred in animals displaying neuronal loss in the 
ipsilateral pirfform cortex suggested that the pathway of seizure propagation may be disrupted by its loss, supporting the idea that this area may be necessary to sustain or possibly to drive ongoing seizure activity (Mcintyre \& Plant, 1989; McIntyre \& Kelly, 1990).

Research implicating the pirfform cortex as an important structure in seizure development inspired McIntyre and Wong $(1985,1986)$ to study the circuitry and response properties of the amygdala/piriform area in vitro. They developed a coronal slice preparation maintaining the integrity of both the amygdala and the piriform cortex in order to preserve the communication between these two areas. Intracellular recordings revealed pirform layer II short burst responses in normal tissue and relatively prolonged burst responses in kindled tissue following amygdala stimulation. Furthermore, the layer II burst response could be evoked from stimulation of the piriform cortex when it was isolated from the amygdala. Since limbic sites such as the amygdala are unable to directly support clonic convulsions, the evoked response observed in the piriform cortex following amygdala stimulation suggested that this area may be pivotal in limbic kindling.

McIntyre and Wong $(1985,1986)$ further demonstrated that the kindlinginduced enhanced amygdala/piriform excitability found in vivo (Kairiss et al., 1984; Racine et al., 1988a) is retained in the slice preparation (McIntyre \& Wong 1985, 1986). Spontaneous bursts were found to exist in approximately half of the slice preparations taken from previously amygdala-kindled rats, whereas virtually no spontaneous burst responses were recorded in control tissue. Furthermore, the piriform cortex had a relatively prolonged burst response following amygdala stimulation in kindled tissue compared to the burst response obtained from control tissue. Thus, in vitro intracellular recordings demonstrate that along with the amygdala, the piriform cortex exhibits a 
permanent increase in excitement following amygdala kindling (Mclntyre \& Wong, 1985, 1986; Gean et al.,1989; Hoffman et at., 1991; Haberly \& Sutula, 1992; Rannie et al., 1992). The enhanced resfonse of the pirfform cortex in vitro in tissue taken from amygdala kindled animals provided further support that the piriform cortex may be critically involved in limbic convulsive networks.

\section{Perirhinal Cortex}

An unexpected discovery by Mclntyre \& Plant $(1989,1991)$ using the amygdala/piriform slice preparation (Mclntyre \& Wong, 1985; 1986) revealed an area of the brain with greater excitability than the piriform cortex had previously shown. The periminal cortex had a greater response to electrical stimulation or to low-magnesium perfusion exposure than that recorded from the piriform cortex (McIntyre \& Plant, 1989; 1991). Under normal perfusion conditions, burst responses developed more rapidly in the perithinal cortex than in the piriform cortex following electrical stimulation. In addition, prior to reducing the magnesium in the perfusate, McIntyre \& Plant $(1989,1992)$ recorded spontaneous discharges from the periminal cortex only. Intrinsic piriform burst responses did not appear under normal perfusion conditions. Spontaneous bursts could be recorded from both the perirhinal and piriform cortex when the $\mathrm{Mg}^{2}+$ in the perfusate was removed; however, the initial perirhinal burst response always preceeded that of the piriform cortex. The excitable nature of the perirhinal cortex suggested that perhaps this area possessed more robust epileptogenic properties than the pirform cortex had previously shown.

The electrophysiological characteristics of the periminal cortex motivated Mcintyre et al. (1993) to investigate the kindling properties of this area in the whole animal. The periminal cortex demonstrates a remarkably greater sensituity to the kindling process than that previously determined from the 
amygdala-pirfform area (Mcintyre et al., 1993). Specifically, it exhibits faster kindling rates and the shortest latencies to the onset of generalized convulsions. The higher stimulus intensity necessary for eliciting an afterdischarge in the perirhinal cortex is not surprising since cortical areas often posses higher thresholds for kindling than subcortical areas. The highly excitable intrinsic properties of the perininal cortex observed in vitro (Mcintyre \& Plant, 1991,1993) may reflect the disruption of inhibitory influences othenwise present in the intact whole animal. However, once the stimulation is intense enough to provoke an electrographic afterdischarge, the number of stimulations required to kindle an animal to a stage 5 convulsion (kindling rate) was less than that observed from other temporal lobe structures. Furthermore, the perirhinal cortex consistently demonstrates latencies to the onset of forelimb clonus in the range of 1-2 seconds, by far the fastest onset to forelimb clonus than any temporal lobe structure previously tested. The rapidly developed, short onset convulsions obtained from repeated stimulation of the perirhinal cortex suggested that this area may have privileged access to motor substrates.

In both the monkey and the rat, the periminal cortex is viewed as a crucial structure in associating limbic to cortical functioning (Saunders et al, 1988; Zola-Morgan et al, 1989), presumably through its extensive cortical and subcortical connections. Cortical afferents of the perirhinal cortex have been reported from the frontal, orbital, parietal, insular, piriform and entorhinal cortex (Kosel et al, 1982; Reep \& Winans, 1982; Deacon et al, 1983; Insauti et al., 1987; Reep et al, 1987; Sesack et al., 1989; Witter et al, 1989; Yasui et al, 1991; Suzuki \& Amaral, 1994a, 1994b). Reciprocal subcortical connections of the perinhinal cortex, especially from the hippocampal formation and the amygdala, have also been reported (Krettek \& Price, 1974; Kosel et al., 1983; Horel et al, 1987; Tumer \& Zimmer, 1984; Saunders \& Rosene, 1988; Stefanaccl et al, 
1992). The hippocampus, a structure repeatedly implicated in memory functioning, exchanges information with several neocortical areas through the perirhinal cortex (Van Hoesen, 1982; Suzuki \& Amaral, 1990) and receives the majority of its cortical input from the perirhinal and entorhinal corticies (Witter ef at., 1989). Lesions of the rhinal cortex (Murray, 1989; Zola-Morgan et al., 1989; Meunier, 1990; Suzuki et al, 1993; Wiig \& Bilkey, 1994), but not of the hippocampus and/or amygdala (Mumby et al, 1992; Miskin, 1978; Aggleton et al 1986; Kesner, 1991; Rothblat \& Kromer, 1991; Mumby \& Pinel, 1994), create severe impairments in certain memory tasks, such as object recognition in both the monkey and the rat. Thus, the perirhinal cortex has recently gained considerable attention in both the kindling and learning and memory literature.

In the context of epilepsy, the kindling properties of the perirhinal cortex suggests that this area may have facile access to motor substrates. Since kindling development was so rapid from the perirhinal cortex, McIntyre et al. (1996) were interested in tracing its efferent connections using the anterngrade tracer Phaseolus vulgaris leucoagglutinin (PhAL). Discrete local injections oi PhAL into the anterior perirhinal cortex were able to show that layer $V$ was the principal source of the broad fiber labeling that was observed in the entire frontal cortex. Injections of the retrograde tracer Fluorogold (FG) into the frontal cortex not only confirmed the layer $V$ periminal input but labeled the perirhinal cortex over its entire rostral-caudal extent. The combined results of these anterograde and the retrograde tracer injections revealed a vast divergentconvergent network of perirhinocortical fibers. Presumably then, kindling in a discrete area of the perirhinal cortex may have direct and widespread influence over the entire frontal cortex, a network that perhaps enables the rapid development of convulsive seizures with short onset latencies. 
The kindling profile, electrophysiological properties, and anatomical cinnections of the periminal cortex is highly suggestive that this area may be the final conduit for propagating limbic discharges to motor structures. A number of experiments implicating the perirhinal cortex as a pivotal structure in the limbic convulsive network have been conducted. Watson et al. (1983) used $\left[{ }^{14} \mathrm{C}\right] 2$-deoxyglucose to visualize the pathway of seizure propagation following the infusion of penicillin into the basal amygdala. Although the basal amygdala has direct anatomical connections to motor cortical regions (Russchen \& Price. 1984; Sripanidkulchai et al., 1984; McDonald, 1987), the focal amygdaloid activity quickly propagates to the piriform/perirhinal cortices. In addition. longlasting increases in the rate of spontaneous unit discharges from both the piriform and the perirhinal cortices following kindling of the basal amygdala have been reported (Teskey \& Racine, 1993). It appears that convulsive discharge from the amygdaloid complex may preferentially utilize its connection with the perirhinal cortex (Krettek \& Price, 1974; Otterson, 1982; Turner \& Zimmer, 1984; McDonald \& Jackson, 1987; Saunders \& Rosene, 1988; Stefanacci et al., 1992; Romanski \& LeDoux, 1993) to access motor substrates necessary for seizure generalization.

In contrast to the connections of the amygdala, direct anatomical connections of the hippocampus to the frontal motor cortex have not been reported. Since the perirhinal cortex has recently been implicated as a critical intermediate structure in the limbic convulsive seizure network, the observation that layer $V$ of the periminal cortex receives input from both the CA-1 hippocampus and the subiculum (Witter et al., 1989) and sends projections to the frontal motor cortex may be a critical connection for seizure generalization from a hippocampal-kindled focus. McIntyre and Kelly (1993) proposed that the rate of kindling achieved from the dorsal hippocampus may reflect intrinsic 
amygdala/pirform/perirhinal excitability since this area was more excitable in animals demonstrating faster kindling rates. These findings provide further evidence that the amygdala/piriform/perirhinal region may be the critical pathway for limbic convulsive discharge, since the intrinsic properties of this area appears to influence the rate of seizure generalization when kindling from the dorsal hippocampus.

A recent study by Kelly (1995) provided results directly supporting a critical role for the perirtinal cortex in dorsal hippocampal kindling. An animal model of status epilepticus (SE) induced by 60 minutes of continuous lowintensity stimulation to a previously amygdala kindled focus results in almost complete loss of the piriform or both the piriform and perirhinal cortex ipsilateral to the kindled amygdala (McIntyre et al, 1982). Following the induction of SE, kindling from the dorsal hippocampus was used to assess the effects piriform/perirhinal damage would have on the normal development of generalized seizures. The normal propagation of hippocampal discharge through the ipsilateral temporal lobe to motor structures supporting the generalized convulsion was disrupted in animals with extensive posterior perirhinal damage. Piriform damage alone was not enough to disrupt the normal profile of kindling from the dorsal hippocampus. These findings suggests that the perirhinal cortex, but not the piriform cortex, is a critical structure in the development of generalized convulsive motor responses when kindling from the dorsal hippocampus.

\section{Objectives and Outline of Proposed Study}

The preceding discussion has provided substantial support for a critical role of the perirhinal cortex in seizure networks involved in limbic kindling. Recent evidence suggest that the perirhinal cortex may be a common 
intermediate site for propagated limbic discharge before projecting to motor structures. The broad innervation of the frontal cortex by the perirhinal cortex could allow limbic discharges that have sufficiently recruited and modified this area to access motor structures necessary for seizure generalization.

The fastest kindling rate and shortest latencies to the onset of forelimb clonus than any other forebrain structure tested was demonstrated in the anterior perirhinal cortex by McIntyre et al. (1993). Since the perı rinal cortex is topographically much bigger than the anterior portion studied, we were interested in examining differences in kindling rates of the whole rostral to caudal extent of this cortex. In addition, laminar differences in perirhinal projections to the frontal motor cortex suggest that there may be laminar differences in kindling rates. Thus, this experiment assessed both topographical and laminar differences in the kindling profile of the entire perirhinal cortex.

\section{MATERIALS AND METHODS}

\section{Animals}

Ninety male Long-Evan Hooded rats (Charles River, Canada), weighing $250-300 \mathrm{~g}$ at the time of surgery, were used in this study. The animals were housed singly with food and water freely available.

\section{Surgery}

Under pentobarbital anesthesia (60 $\mathrm{mg} / \mathrm{kg}$, i.p.), the rats were implanted with bilateral electrodes into one of four anterior to posterior locations within the periminal cortex. The four different locations will be referred to as groups 1, 2 , 3. and 4. The stereotaxic coordinates were $0.2 \mathrm{~mm}$ posterior to bregma, 4.2 to 
$5.3 \mathrm{~mm}$ lateral to midline angled at $14^{\circ}$ and $7.1 \mathrm{~mm}$ deep for the first group; 2.2 $\mathrm{mm}$ posterior to bregma, 4.3 to $5.6 \mathrm{~mm}$ lateral to midline angled at $14^{\circ}$, and 7.3 $\mathrm{mm}$ deep for the second group; $4.2 \mathrm{~mm}$ posterior to bregma, 4.8 to $5.5 \mathrm{~mm}$ lateral to midline angled at $14^{\circ}$, and 7.5 deep for the third group; and $6.2 \mathrm{~mm}$ posterior to bregma, 5.0 to $5.5 \mathrm{~mm}$ lateral to midline angled at $14^{\circ}$, and $4.8 \mathrm{~mm}$ deep for the fourth and most posterior perirhinal cortex group.

Electrodes constructed with two twisted strands of $127 \mu \mathrm{m}$ diameter Nichrome wire, Diarnel-insulated, attached to male Amphenol pins were cut to length then surgically implanted using a Kreig stereotaxic instrument. Six jewelers screws allow the electrodes to be fixed to the skull by dental acrylic and placed into a headplug assembly. Kindling began one week following surgery.

\section{Kindling}

On the first day of kindling, the afterdischarge (AD) threshold, defined as the minimum stimulus intensity to provoke an $A D$ outlasting the stimulus by $2 \mathrm{~s}$ or more, was determined in one randomly chosen electrode site in all rats. A progressive increase in stimulus intensity of $2 \mathrm{~s}, 60 \mathrm{~Hz}$ sine wave was given $60 \mathrm{~s}$ apart until an $A D$ is evoked. The stimulus intensity increments chosen were 10 $\mu \mathrm{A}$ from 10 to $100 \mu \mathrm{A}, 25 \mu \mathrm{A}$ from 100 to $200 \mu \mathrm{A}, 50 \mu \mathrm{A}$ from 200 to $400 \mu \mathrm{A}$, and approximately $200 \mu \mathrm{A}$ from 400 to $1250 \mu \mathrm{A}$ peak-to-peak. Kindling began 24 hours following the $A D$ determination.

Kir.dling involved daily stimulation of the site chosen for initial AD determination. This stimulus consisted of a $2 \mathrm{~s}, 60 \mathrm{~Hz}$ sine wave at one increment below the intensity that achieved an $A D$ on the previous day. If an $A D$ was not elicited at this lower stimulus intensity, it was increased by one higher increment every $60 \mathrm{~s}$ until an $A D$ is evoked. In this way, $A D$ thresholds 
vere monitored daily during the kindling process. Convulsive behaviour was classified according to Racine's five stages (1972), as indicated in the introduction. The rats received one stimulation/day until six stage 5 convulsions were recorded. The $A D$ threshold was determined again one day following the last stage 5 seizure.

\section{Histology and data analysis}

Following the completion of kindling, under deep anesthesia. all rats were perfused intracardially with saline followed by $10 \%$ formalin. Electrodes were then removed one day later and the brains stored in $10 \%$ formalin fixative for a minimum of three days prior to sectioning. To identify both the laminar and topographic position of each electrode placement, frozen serial sections of $40 \mu \mathrm{m}$ were taken through the electrode tract and stained with Cresyl violet.

The data were analysed parametrically using analysis of variance and. when appropriate, group comparisons were made with Scheffe's test. The dependent measures of interest for each animal were: (1) the initial afterdischarge (AD) threshold and its duration; (2) the kindling rate, defined as the number of stimulations necessary to elicit the first stage 5 convulsion; (3) the profile of the six stage 5 convulsions, including the convulsion latencies (the length of time from stimulus onset to the onset of forelimb clonus) and durations; (4) the total el ectrographic AD duration; and, (5) the final AD threshold which was tested one day following the sixth stage 5 convulsion. 


\section{Results}

Histological examination confirmed electrode placements to be located either superficially (layers I-III) or deep (V, VI) within the 4 desired anterior to posterior areas of the perirhinal (PRh) cortex (Figure 1).

\section{Initial Thresholds}

On the initial threshold trial, increments of electrical stimulation were applied to the same electrode for two seconds at intervals of one minute apart until an observable electrographic after discharge (AD) was produced. Increases in the intensity of the stimulation were terminated if an $A D$ was not produced by $1250 \mu \mathrm{A}$. Assessment of the initial AD thresholds between the 4 PRh groups revealed a significant $(p<0.0001)$ topographical difference that was attributed to the high AD threshold of the most caudal PRh group (group 4) (Table 1). In addition, a main effect of initial AD threshold between superficial and deep layers also existed since superticially placed electrodes required significantly ( $p<0.0002)$ higher intensities of stimulation to elicit an $A D$ than the deeper layers (Table 2).

Although a number of animals with electrode placements in the superticial layers of groups 1 and 2 had thresholds that exceeded $1250 \mu \mathrm{A}$, the remaining animals in these groups possessed soniewhat lower thresholds for producing an initial $A D$. However, the thresholds for triggering an $A D$ on the second stimulation trial for most of these animals that had lower first trial $A D$ thresholds increased into the range of $1250 \mu \mathrm{A}$ (or higher). Furthermore, the superticial layers of groups 1 and 2, and both the superficial and deep lamina of group 4 needed several days of stimulation at $1250 \mu \mathrm{A}$ before an electrographic discharge could be evoked or re-evoked. In contrast to the high superficial 
FIGURE 1. Schematic diagram taken from Swanson (1992) showing the electrode tip location of each rat of the 4 perirhinal cortex kindled groups. Electrode tips are indicated by filled circles. 

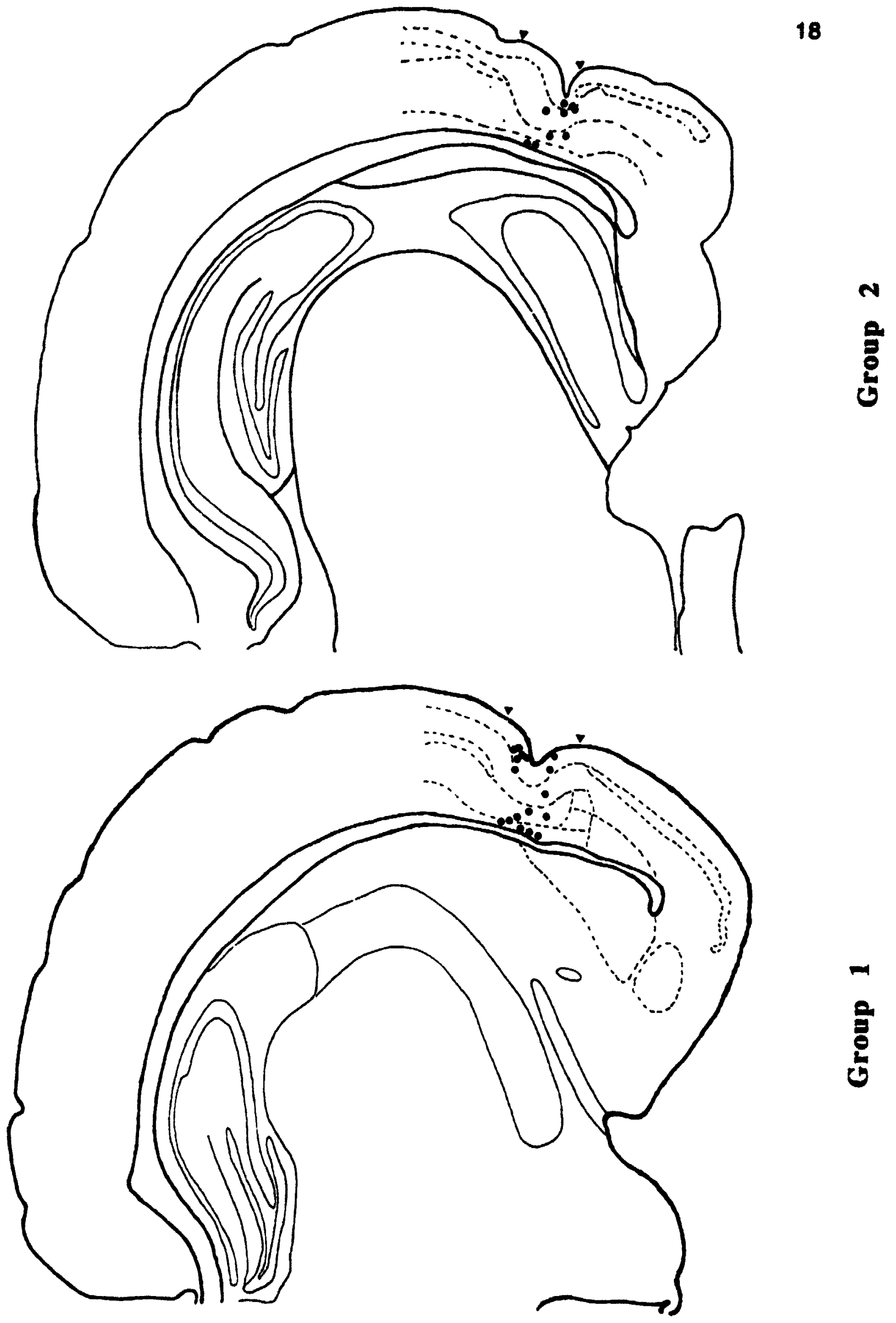

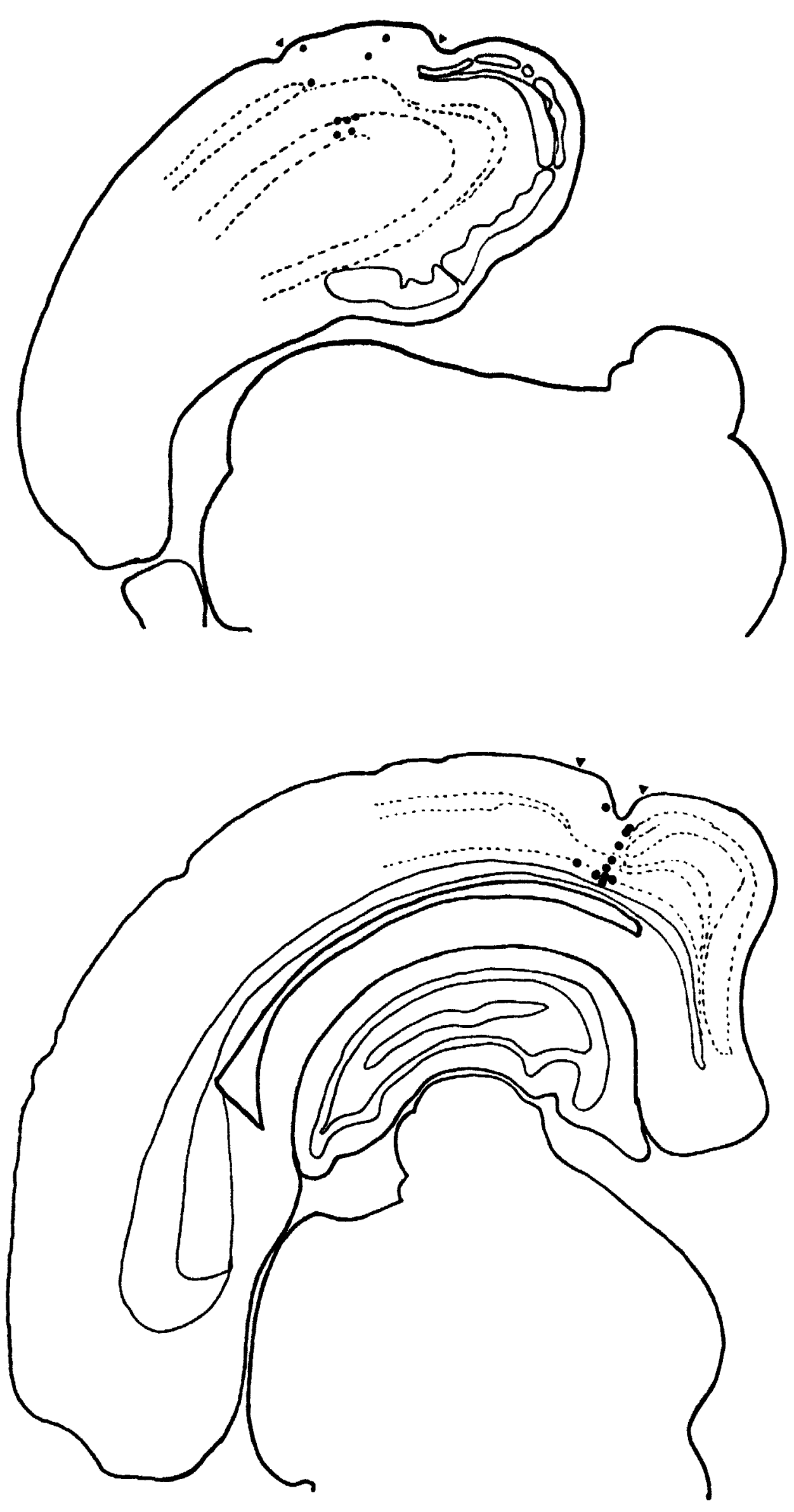

룽 
TABLE 1

The mean ( \pm S.E.M.) initial and final afterdischarge (AD) and stimulus bound (SB) thresholds in $\mu \mathrm{A}$ in 4 groups of rats, each kindled from 1 of 4 different anterior to posterior locations in the perirhinal cortex (see method).

\begin{tabular}{|l|c|c|c|c|}
\hline Group & $\begin{array}{c}\text { Initial AD } \\
\text { Threshold }\end{array}$ & $\begin{array}{c}\text { Final AD } \\
\text { Threshold }\end{array}$ & $\begin{array}{c}\text { Initial SB } \\
\text { Threshold }\end{array}$ & $\begin{array}{c}\text { Final SB } \\
\text { Threshold }\end{array}$ \\
\hline 1 & $336.1 \pm 84.5$ & $136.9 \pm 30.9$ & $170.3 \pm 67.4$ & $68.3 \pm 13.0$ \\
\hline 3 & $566.0 \pm 154.6$ & $117.5 \pm 38.8$ & $221.5 \pm 66.8$ & $52.0 \pm 7.9$ \\
\hline 4 & $454.5 \pm 78.8$ & $145.5 \pm 49.0$ & $404.4 \pm 85.1$ & $63.2 \pm 12.7$ \\
\hline
\end{tabular}

* = Significantly different from all other groups, $p<0.05$ 
TABLE 2

The mean ( \pm S.E.M.) initial and final afterdischarge (AD) and stimulus bound (SB) thresholds in $\mu \mathrm{A}$ in rats kindled from either superficial or deep perirhinal (PRh) cortex locations.

\begin{tabular}{|l|c|c|c|c|}
\hline Laminae & $\begin{array}{c}\text { Initial AD } \\
\text { Threshold }\end{array}$ & $\begin{array}{c}\text { Final AD } \\
\text { Threshold }\end{array}$ & $\begin{array}{c}\text { Initial SB } \\
\text { Threshold }\end{array}$ & $\begin{array}{c}\text { Final SB } \\
\text { Threshold }\end{array}$ \\
\hline Superticial & $747.8 \pm 93.4^{*}$ & $200.7 \pm 30.1^{*}$ & $531.3 \pm 94.1^{*}$ & $94.3 \pm 9.8^{*}$ \\
\hline Deep & $421.5 \pm 85.3$ & $61.3 \pm 6.3$ & $236.5 \pm 66.1$ & $42.7 \pm 3.9$ \\
\hline
\end{tabular}

* = Significantly different from the deep PRh group, $p<0.05$ 
initial or second-day thresholds of groups 1 and 2, the deeper PRh layers of these groups had much lower thresholds and did not demonstrate second-trial increases in the intensity necessary to elicit an AD. It appears that, compared to all other PRh areas, AD responses were easily triggered from the deep layers of the anterior PRh cortex.

During the intial $A D$ threshold stimulation trial, it was observed that stimulus-locked behavioral motor responses (stimulus bound behavior) were often elicited during the 2 second stimulation period at intensities that did not evoke an AD. These behaviors consisted mostly of ipsilateral turning behavior, backing up, or stage 1 - 2 mastication. Comparisons of both topographical and laminar thresholds at which stimulus bound (SB) behavior was first evoked were also made.

A statistical analysis of initial SB thresholds revealed both topographical and laminar main effects. Similar to the AD threshold comparisons, the threshold for eliciting SB behavior was higher in group 4 ( $p<0.0001)$ compared to the other 3 groups (Table 1), and, collapsing over the 4 groups, the stimulus intensity necessary to elicit SB behavior superficially was significantly higher than that required in the deeper PRh layers (Table 2). Since stimulation of superticial PRh lamina in groups 3 and 4 did not produce SB behaviors before an $A D$ was evoked, it is important to note that the $A D$ thresholds were used for these SB threshold measures in this analysis. The lack of SB motor behaviors at the high intensities required to evoke an $A D$ from the superficial areas of these two groups suggested that the neurons stimulated by these superficial electrode placements did not posses direct connections with motor substrates. Conversely, the superficial lamina of the rostral PRh cortex (groups 1 and 2) may be able to access motor areas more easily since SB behavioral responses could be evoked from these areas at intensities lower than $1250 \mu \mathrm{A}$. However, 
If electrical stimulation produced motor responses in the superficial layers of groups 1 and 2 before an AD was produced, the intensity necessary to drive these SB motor responses was relatively high compared to the deep layers. in fact. SB motor responses could always be evoked from the deep layers of all PRh groups at lower thresholds.

\section{Kindiling Rate}

Subsequently, all animals were kindled by a 2 second daily stimulation using a stimulus intensity that was one increment below the intensity that elicited an $A D$ on the previous day. If an $A D$ was not evoked with a particular stimulus, the intensity was increased by one increment every 60 seconds until an $A D$ was triggered. Interestingly, in contrast to the differences found in the initial SB and AD threshold analysis, there were no topographical or laminar main effects of kindling rate (KR). Since there was a significant topography by laminar interaction, multiple comparisons were made between the 8 PRh groups. This analysis revealed that the deep layers of group 1 kindled in significantly fewer trials than the deep layers of group 2 and the superficial iayers of group 3 (Figure 2). Although these were the only significant differences between the groups in KR, it appeared more generally that, except for group 2, the superficial layers kindled slower than the deep PRh lamina. It is important to remember that although the kindling rates were achieved in a statistically similar number of stimulation trials between superficial and deep PRh cortex, the stimulus intensity applied to superficial layers was much higher.

\section{Convulsion Measures}

A number of measurements taken from the six stage-5 convulsions for each animal showed additional significant topographical and laminar 
FIGURE 2. Mean ( $t$ S.E.M.) kindling iate to the first stage-5 convulsion for all 8 perirhinal ( $P R h$ ) subgroups, the 4 topographic groups subdivided into deep vs. superticial subgroups $(n=4-9)$. 


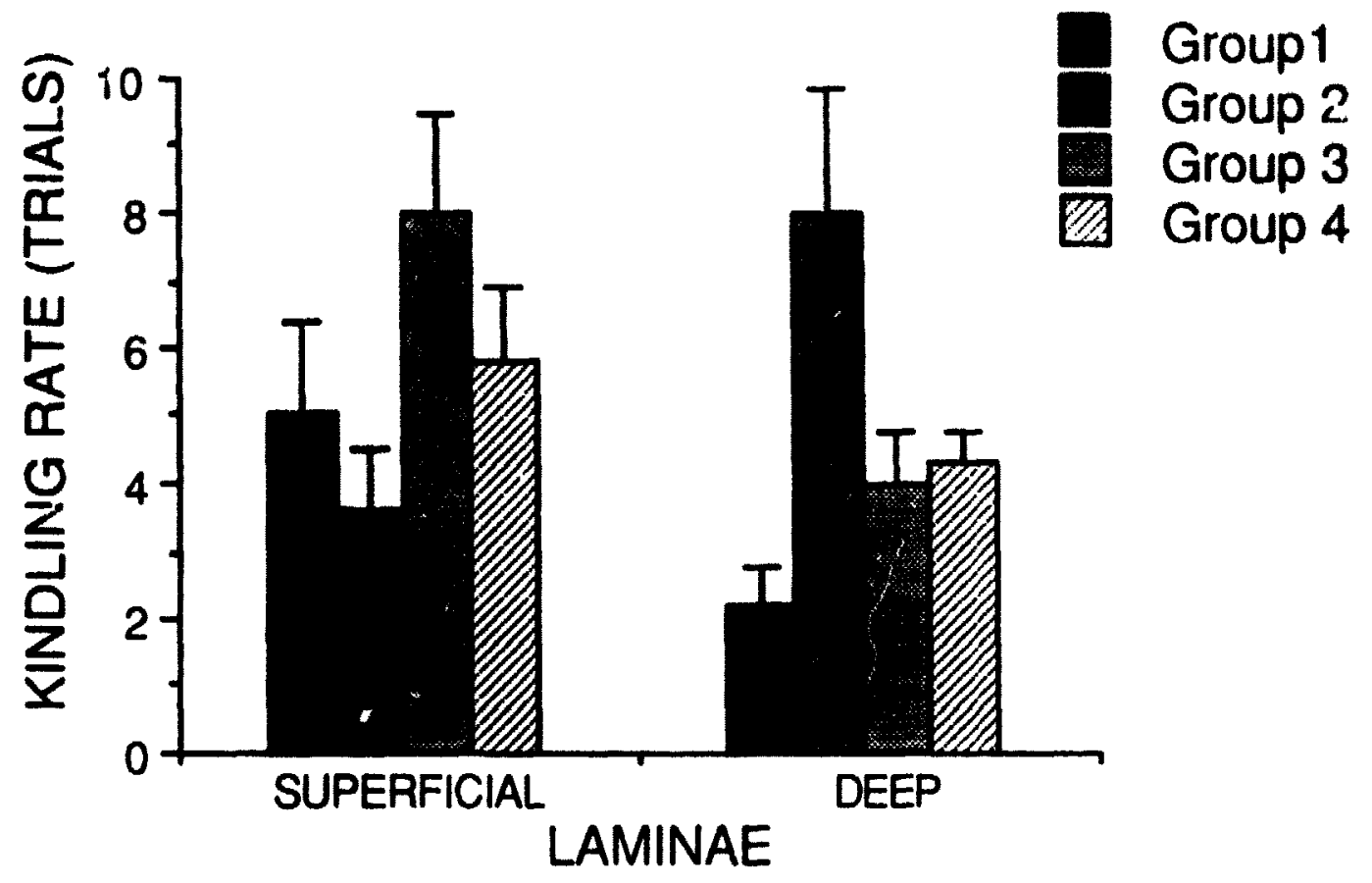


differences in the convulsion profile of each PRh group or area. An analysis of the latency from stimulus onsel to the initiation of forelimb clonus revealed a significant difference between the 4 anterior to posterior PRh groups.

Specificyally, group 1 demonstrated significantly shorter $(p<0.0001)$ latencies than groups 2,3, and 4 (Figure 3). Furthermore, ignoring group membership, deep PRh layers presented significantly $(p<0.006)$ shorter durations to the onset of forelimb ctonus than those shown by the superficial layers (Figure 3). It appears from the threshold and latency analysis that the deep PRh layers may possess more intimate connections with motor substrates since this area demonstrated much lower thresholds for both initial ADS and SB behaviors and extremely fast latencies to the onset of generalized convulsions compared to the superficial layers.

In addition to the group and laminar main effects of convulsion latencies, a significant topography by laminar interaction existed. Multiple comparisons between the 8 PRh groups revealed significantly longer ( $p<0.0004)$ superficial groups 3 and 4 latencies than the latencies found in the other 6 PRh areas (Figure 3). The deep layers of all four groups and the superficial layers of groups 1 and 2 accessed motor substrates involved in the generalization of convulsions faster than the superficial lamina of groups 3 and 4 . Therefore, the convulsive discharges initiated from the most rostral PRh region and the deeper PRh lamina tapped into networks involved in the generalization of motor seizures more rapidly than convulsive discharges from the other PRh areas.

Throughout the kindling process, the durations of the clonic motor convulsive discharge and the total AD durations were measured. A significant topographical group difference in both convulsion duration (p<0.002) and associated AD duration ( $p<0.0001$ ) was found for group 3 . Group 3 demonstrated significantly longer convulsions (Figure 4) and total ADs 
FICURE 3. Mean ( \pm S.E.M.) latency to forelimb clonus of the 6 stage-5 convulsions for all 8 perirhinal (PRh) subgroups, the 4 topographic groups subdivided into deep vs. superficial subgroups $(n=4-9)$. 


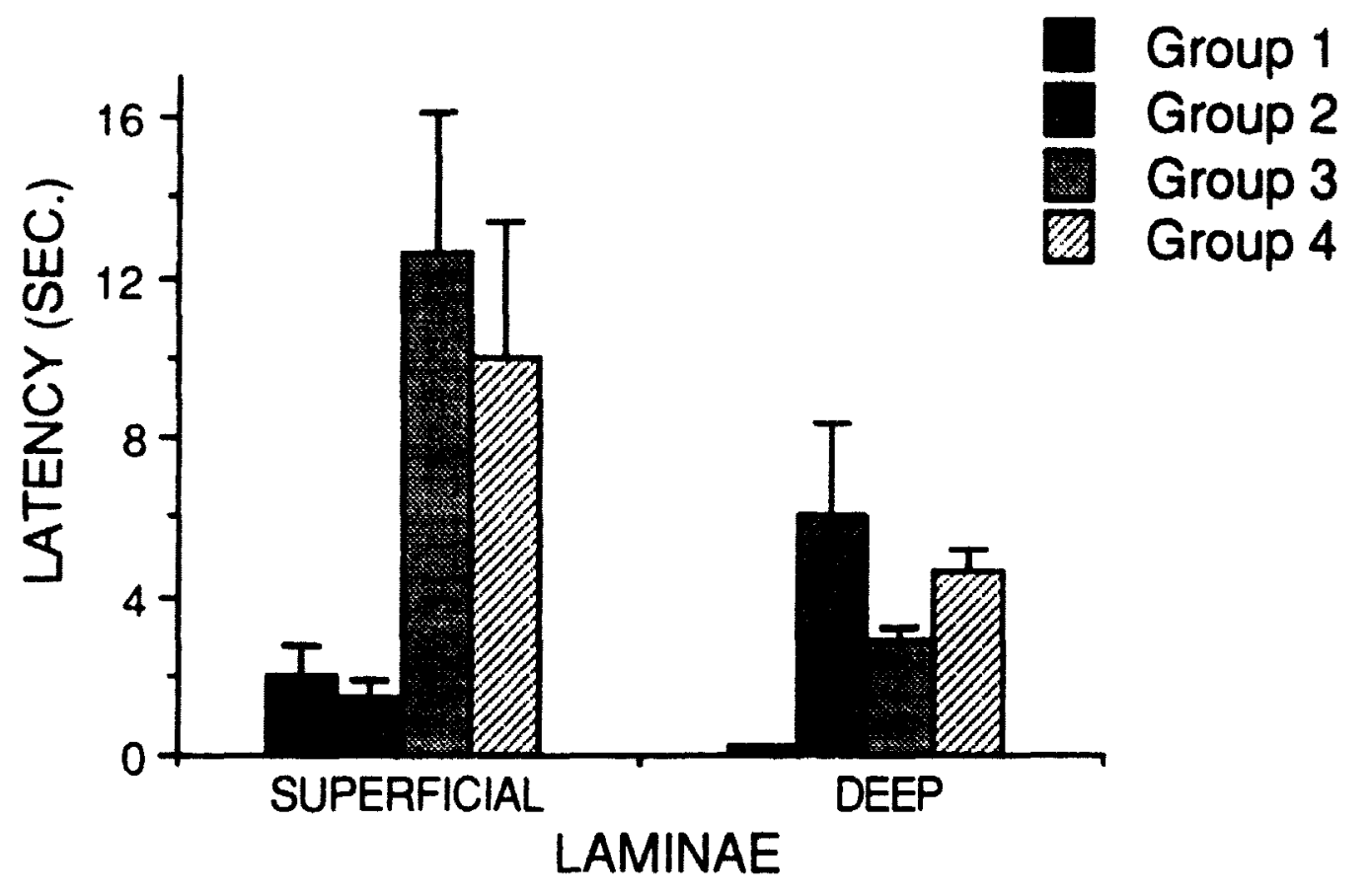


FIGURE 4. Mean ( \pm S.E.M.) convulsion duration (duration of forelimb clonus) of the 6 stage- 5 convulsions for the 4 topographical perirhinal (PRh) groups. 


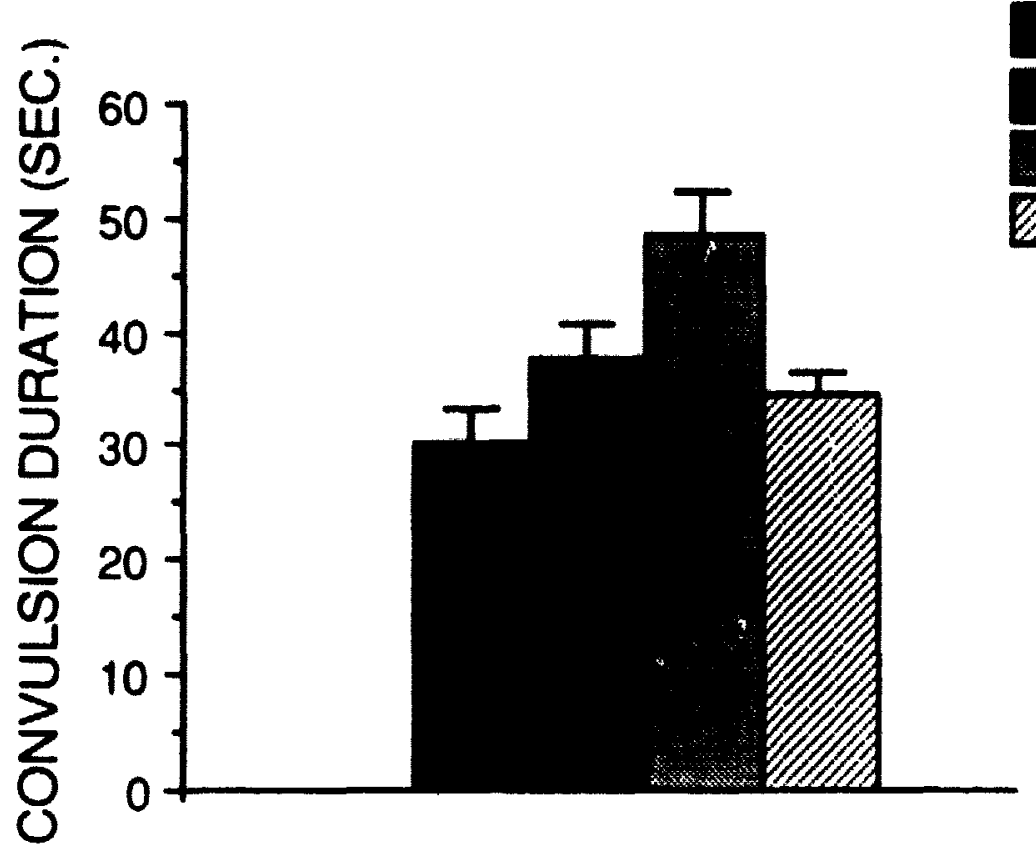

Group 1

Group 2

Group 3

छroup 4 
durations (Figure 5) than each of the other three groups. Conversely. a main effect of lamina did not exist since significant differences in convulsion and total $A D$ durations were not apparent between superticial and deep PRh layers.

\section{Final Threenolde}

Similar to the method of measuring the initial SB and AD thresholds, final thresholds were taken one day following the last stage-5 convulsion. In contrast to the topography main effect of both the initial SB and AD threshold trials. significant final threshold differences between the 4 PRh groups were not apparent. Unlike the notably high intensity required to elicit an initial AD from group 4, much lower thresholds were able to trigger convulsive discharges once kindling had taken place. Kindling appeared to alter the threshold response properties of the most rostral PRh group to subsequent stimulation.

Similar to the laminar main effect of both the initial $A D$ and SB thresholds, final thresholds were significantly $(p<0.0001)$ lower in deep PRh layers compared to the superficial layers (Table 2). Although the AD and SB thresholds of all PRh placements were lower for the final measure, significant differences between superficial and deep PRh areas still existed. Figure 6 and 7 illustrates the dramatic decrease in $A D$ thresholds between the initial to the final trial. Kindling appeared to alter the response properties of the whole PRh cortex so that it became inherently more sensitive to stimulation; however, the deeper layers consistently possessed lower AD and SB thresholds than the superficial layers regardless of prior stimulation experience.

In addition to the AD threshold reduction found between the first and final trials, there was a large decrease in the intensity necessary to trigger SB motor responses in all the PRh areas (Figures 8 and 9). Since stimulation of the superficial layers in group 4 did not provoke any SB motor responses before an 
FIGURE 5. Mean ( \pm S.E.M.) after-discharge (AD) duration of the 6 stage-5 convulsions for the 4 topographical perirhinal (PRh) groups. 


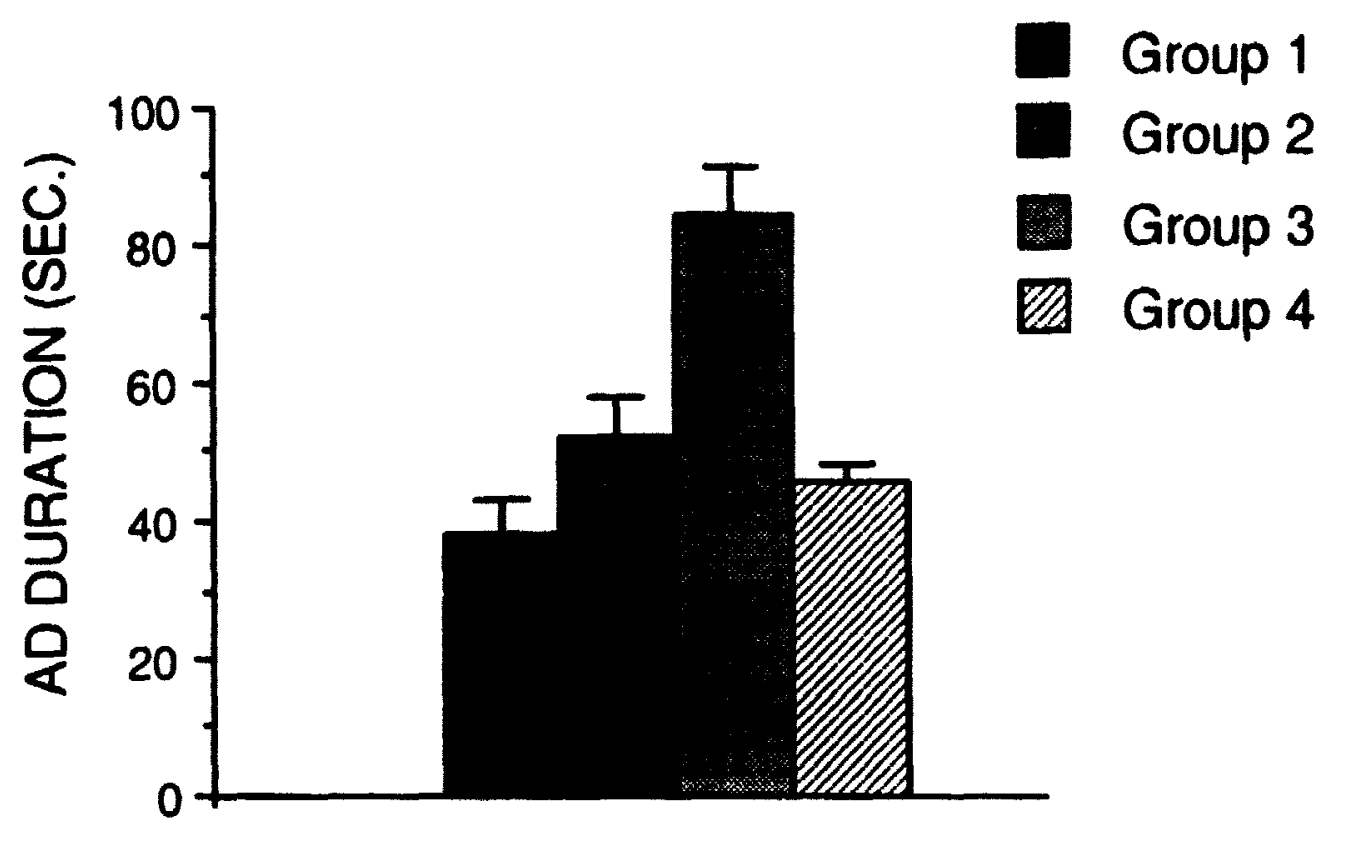


FIGURE 6. Mean ( + S.E.M.) initial and final threshold at which an afterdischarge (AD) was produced for the 4 topographical periminal (PRh) groups. 
TOPOGRAPHY

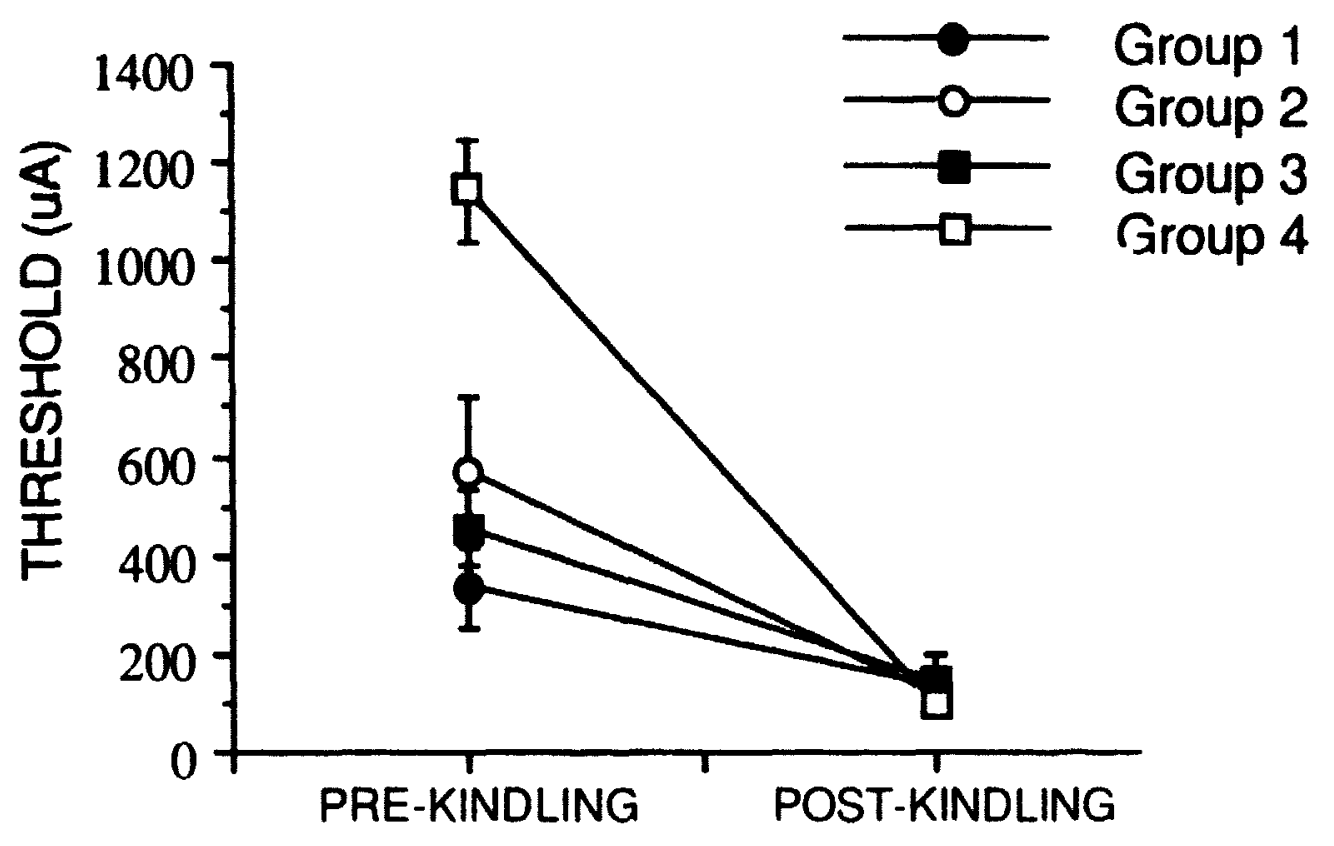


FIGURE 7. Mean ( $t$ S.E.M.) initial and final threshold at which an afterdischarge (AD) was produced for the 2 laminar periminal (PRh) groups. 


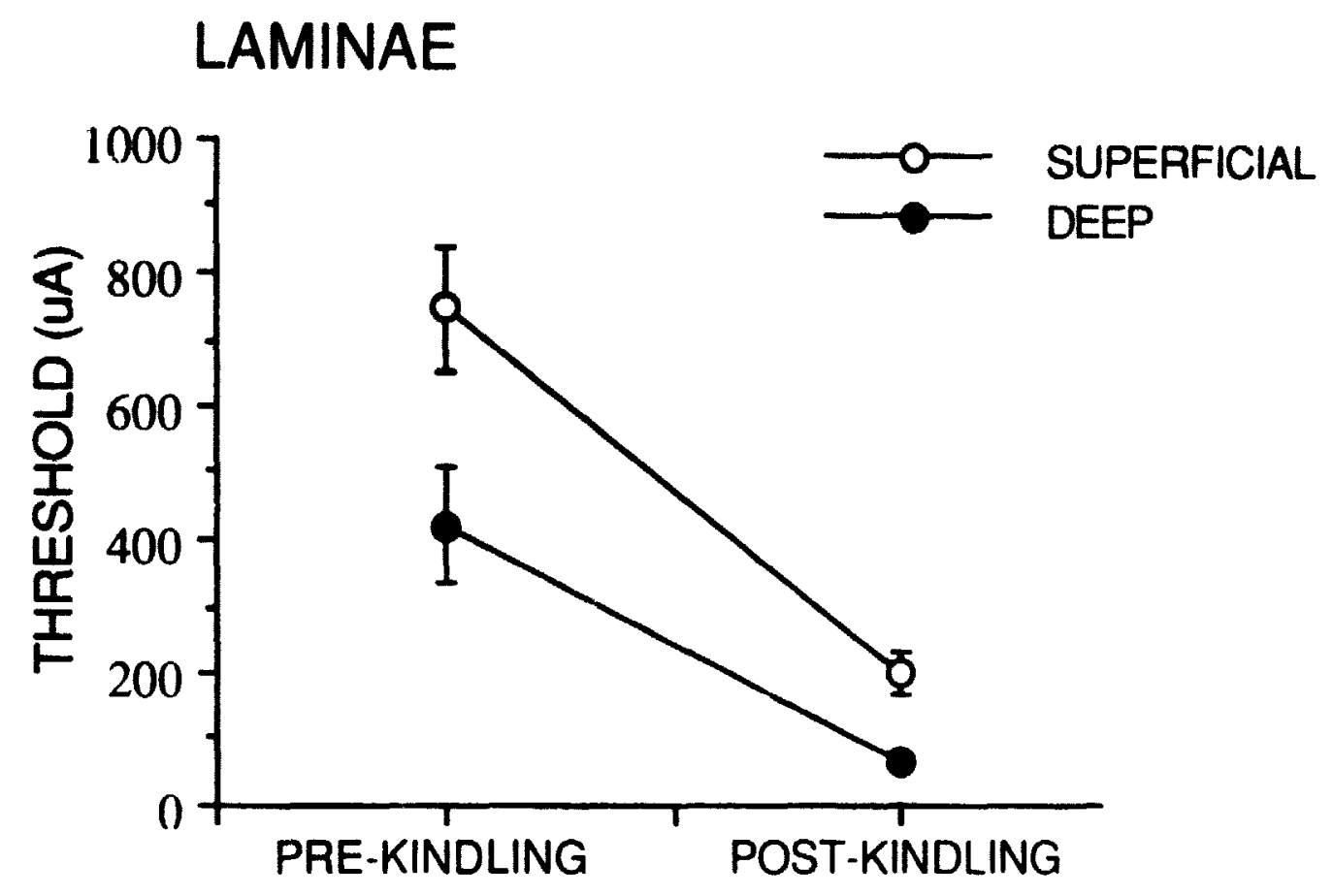


FIGURE 8. Mean (tS.E.M.) initial and final threshold at which stimulus bound (SB) motor behaviors were produced for the 4 topographical perirhinal (PRh) groups. 


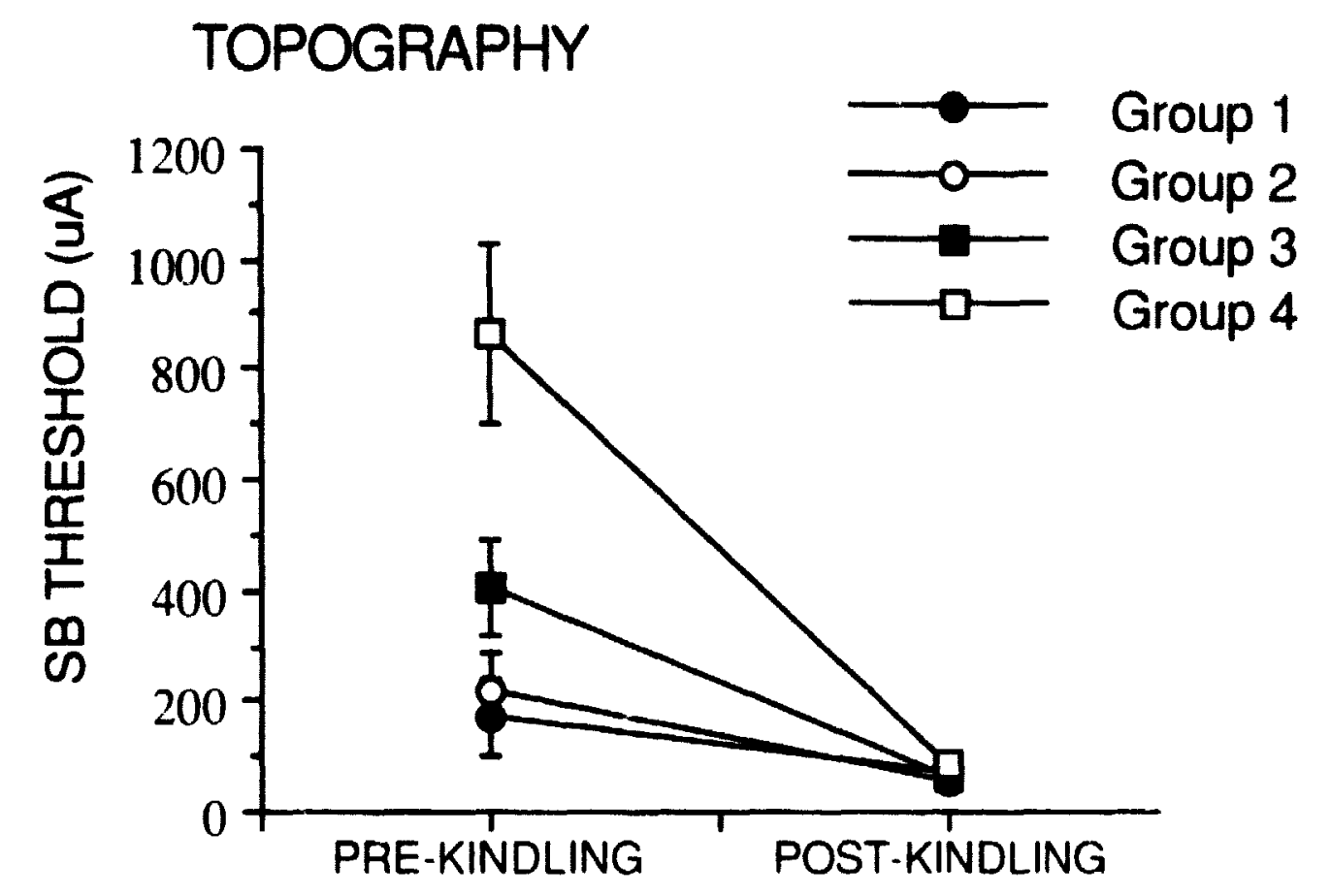


FIGURE 9. Mean (+S.E.M.) initial and final threshold at which stimulus bound (SB) motor behaviors are produced for the 2 laminar perirhinal (PRh) groups. 


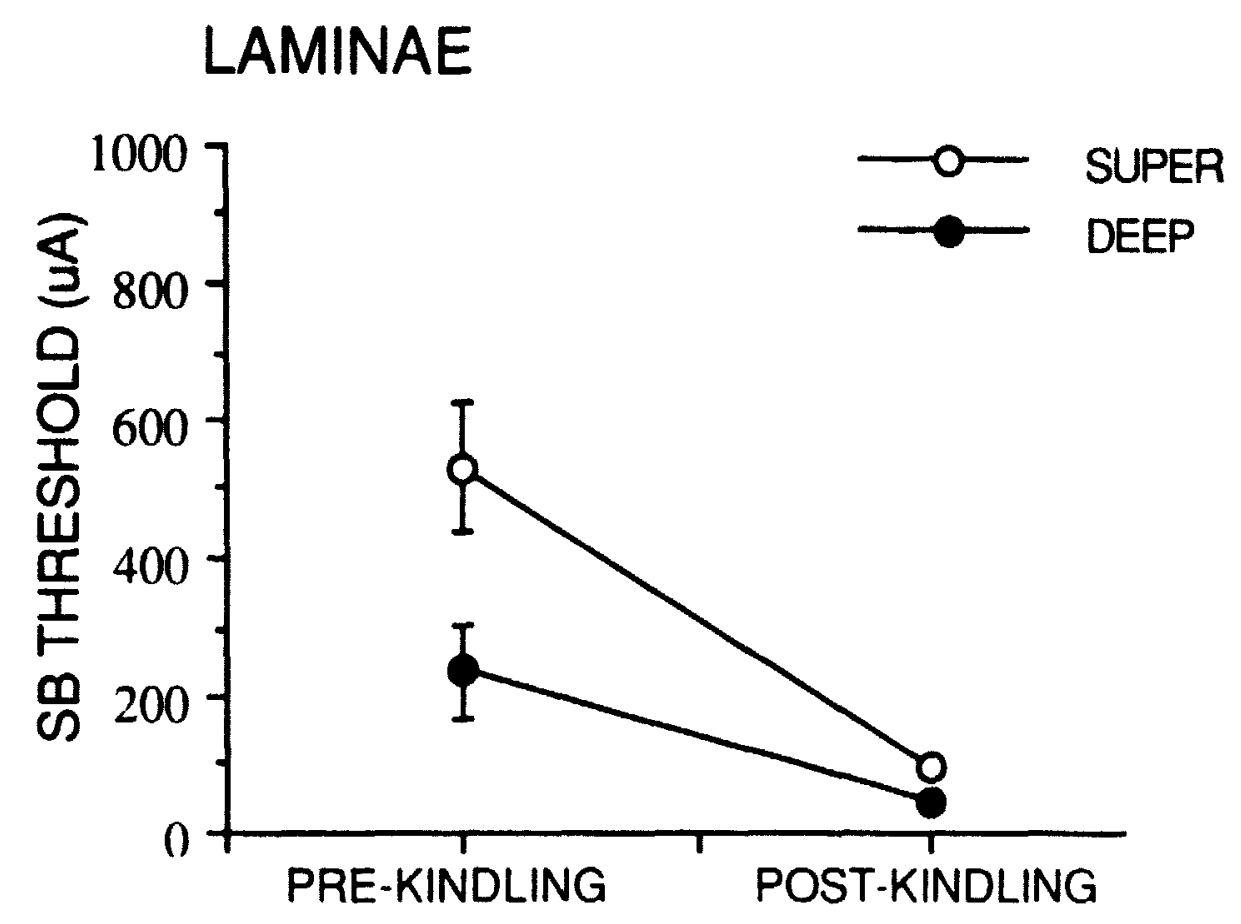


$A D$ was triggered in both initial and final SB threshold trials, the corresponding AD threshold measures were used for the SB analysis. It is important to keep in mind that in contrast to the initial threshold intensities that reached $1250 \mu \mathrm{A}$ without any observable SB behaviors or electrographic ADs, motor convulsions were evoked during final threshold trials at intensities in the range of $150 \mu \mathrm{A}$ in this area. However, even though motor structures were accessed for seizure generalization at fairly low thresholds from the superticial layers of group 4 during the final threshold trial, the electrical stimulation did not appear to excite motor networks during the $\mathbf{2}$ second stimulation period.

In contrast to the initial lack of SB responses to electrical stimulation for the superficial layers of group 3, very interestingly, this group demonstrated SB behavioral responses during the final threshold tests. Thus, it appeared that this superficial PRh area was modified during the kindling process to gain access to motor networks that were previously unavailable. These networks could then activate and/or drive motor responses before a convulsive discharge was triggered.

\section{Discussion}

In general, we have observed that subregions within the perirhinal (PRh) cortex respond differentially to low-intensity electrical stimulation that triggers 'stimulus bound' (SB) behaviors and/or the after-discharges (AD)s leading to kindling. With the view that the PRh cortex is commonly recruited as part of the limbic convulsive network, the implication of cur findings to our understanding of mechanisms involved in temporal lobe seizures is discussed. We feel that particular regions within the 
PRh cortex demonstrate the brain's greatest sensitulity to electrical stimulation and kindling, and may be most crtically involved in eplleptogenictly. In parallel to the organization of the results section, we will first discuss the threshold data for triggering ADs and SB behavior. This will be followed by a discussion of the kindling rates, convulsion profiles, and final $A D$ and SB threshold data.

Initial threshold

AD thresholds The lowest thresholds for both the electrographic ADs and SB behaviors were triggered from the most anterior deep PRh areas (group 1) which progressively increased as the electrode placements moved posterior to group 4 within the deep layers. In contrast to the low thresholds found in the deep PRh lamina, all superficial layers as well as all layers of group 4 were highly resistant to developing electrographic ADs. Since some of the animals with electrode placements in the anterior superficial lamina demonstrated much higher AD thresholds on the second day of stimulation, it appears that this area is either initially inhibited, or becomes so once an initial priming stimulus is administered. Regardless of whether a high threshold response was achieved on the first or second trial, the superficial areas of all groups and all layers within the most caudal PRh group are unable to readily respond to high intensity electrical stimulation with an AD.

It is not surprising that in general the initial in vivo PRh AD thresholds are high compared to other well-documented limbic structures (McIntyre et al., 1993) since neocortical sites often possess higher $A D$ thresholds relative to subcortical areas (Burnham, 1978). The ability to provoke PRh responses at very low thresholds in the slice preparation may be attributed to the disruption of inhibitory networks responsible for suppressing PRh excitability in the whole animal. However, despite the inhibitory influences that may be present in the 
whole animal, the sensitivity of the more anterior regions of layer $V$ to electrical stimulation became very apparent during the initial threshold trial.

We anticipated that the deep PRh layers would demonstrate the greatest sensitivity to stimulation since Battye and McIntyre (unpublished results) previously discovered unique excitable characteristics of this same PRh area in vitro. Not only did calls in layer $V$ respond to intracellular depolarizing current injections at much lower thresholds than cells in any other PRh layer, but uncharacteristic 'epileptic' responses were unique to this PRh laminae. Unlike the surrounding cells in the other PRh layers, depolarizing current injections delivered to layer $V$ easily triggered burst response firing of multiple action potentials riding on a large depolarizing envelope. The ability of layer $V$ cells to sustain triggered discharges suggests that they may be highly interconnected, and capable of synchronizing responses in target cells. It appears that the highly excitable, low threshold response of layer $V$ in the slice preparation is retained in the whole animal. More specifically, it seems that the anterior deep layers are, at least initially, more excitable in response to local electrical stimulation than any other PRh area.

SB thresholds Unlike other limbic structures such as the pirfform cortex, amygdala, or dorsal hippocampus, stimulation of the PRh cortex has been shown to trigger stage-1 seizure behavior during the initial AD threshold trial (McIntyre et al., 1993). In addition to observing stage-1 responses during the initial electrographic $A D$, we found the majority of rats subjected to PRh stimulation demonstrated convulsive motor behaviors that were tied to the 2 second stimulation period at intensities lower than the animals $A D$ threshold. Although this motor behavior was seldom elicited from structures outside the PRh cortex, SB motor behaviors progressing from stage 1 at low stimulus 
intensities to stage 2, 3, or 4 at higher intensities were observed during the first trial within many PRh areas.

Stimulus-locked motor behavior was easily evoked from the deep lamina of groups 1, 2, and 3 at relatively low thresholds. In contrast to the ease with which these deep PRh areas drove structures involved in triggering SB motor behaviors, stimulation of the superficial lamina did not readily elicit these kinds of responses. Whereas high stimulus intensities for triggering SB motor behaviors were required for the superficial lamina of groups 1 and 2, these layers of groups 3 and 4 did not demonstrate any kind of observable SB motor behaviors during the initial threshold trial. The strong stimulus intensity applied to these areas, with or without triggering any observable SB behaviors. suggests that the superficial lamina are either highly inhibited and therefore unable to excite target areas, or lack strong connections with motor areas involved in stimulus-locked behavior. Sirrce SB motor behavior provides cogent information on the ease with which an area can influence motor structures involved in the limbic convulsive network, it appears that the deep PRh layers may have the most facile access to motor mechanisms involved in motor convulsions.

The ability to rapidly access motor structures via layer $V$ stimulation may reflect frontal cortex activation. In the cat, Witter and Groenewegen (1986) had previously shown dense PRh projections to frontal motor areas originating from cells in layers V and VI. Similarly, discrete PhAL anterograde tracer injections placed into the anterior PRh cortex of the rat by McIntyre et al. (1996) revealed layer $V$ as the major source of frontal cortex labelling. Although PhAL injections restricted to the anterior regions prevented them from studying the efferent topography of the PRh cortex, injections of the retrograde tracer flourogold into the frontal cortex allowed them to observe extensive filling of cells 
predominantly in layer $V$ throughout the entire anterior to posterior extent of the PRh cortex. Although the PRh cortex projects to a number of structures that could support the motor component of generalized limbic seizures (McIntyre of al., 1996), the rapidly developed, short-onset convulsions triggered from the anterior PRh cortex (McIntyre et al., 1993) could most readily be explained by the direct connections with the frontal motor cortex. Since it is layer $V$ of the PRh cortex that massively innervates frontal cortex motor areas, it is not surprising that SB motor responses can be easily triggered by stimulating the deep PRh layers.

\section{Kindling Rate}

Based on the dense anatomical connections with the frontal motor cortex and the highly excitable characteristics of PRh layer V cells, we anticipated a significant kindling rate (KR) difference between the superticial and deep layers. Contrary to this expectation, we found the deep PRh layers to kindled only slightly more rapidly than the superficial lamina. Although this was somewhat surprising, it is important to keep in mind that the high stimulus intensities necessary to trigger electrographic ADs in the superficial layers likely confounded any laminar differences in KR that may have existed. Whereas deep layers kindled rapidly at low thresholds, superficial layers kindled marginally slower at much higher thresholds. Perhaps the extremely high intensity stimulation applied to the superficial PRh layers enabled direct activation of the layer $V$ cells. Therefore, whether layer $V$ cells where directly activated by stimulation of the deep PRh layers or less directly by activation of the superficial layers, sustained convulsions would be achieved in a similar and minimum number of trials. 


\section{Convulaton Measures}

Latencies Although in general the deep PRh layers presented the shortest latencies to the onset of sustained forelimb clonus, the speed at which the deep lamina of group 1 tapped into the mechanisms involved in the motor component of a convulsion was significantly faster than all other PRh areas. Conversely. the superficial layers of groups 3 and 4 that were unable to produce SB motor behavior demonstrated the longest latencies to the onset of forelimb clonus during their kindled convulsions compared to all other PRh groups. The explanation for this difference likely rests in the anatomical connections. Unlike the massive connections of layer $V$ cells to the frontal motor cortex, the superficial layers possess relatively sparse frontal cortex projections (Mcintyre et al., 1996). If the frontal cortex is critical to lim!sc seizure generalization, stimulation of superficial posterior PRh layers may take some time to either directly excite the frontal motor cortex through its sparse projections or, more likely, excite layer $V$ cells that massively innervates the necessary frontal area.

Evidence suggests that the frontal cortex area may in fact be involved in convulsions kindled from a number of limbic areas. It was previously demonstrated that sustained amygdala kindled motor responses can be triggered with significantly fewer stimulation trials than that necessary to establish sustained motor responses from the frontal cortex (Wada et al., 1974; Wake \& Wada, 1976; Burnham, 1978). At first glance, the greater resistance of the frontal cortex to develop sustained seizures compared to a limbic structure suggested that this area may not be critically involved in the convulsive network. However, the overlapping projections to entire frontal cortex by the PRh cortex suggests that recruitment of this area during limbic kindling could very quickly develop sustained discharges synchronizing all of the frontal cortex (McIntyre et al., 1996). Since kindling stimulation in the frontal cortex initially involves only a 
relatively discrete area around the electrode tip, It may take many repeated stimulations for the local frontal cortex after-discharges to recruit surrounding frontal cortical areas. Therefore, it is quite possible that limbic structures could produce sustained motor seizures more rapidly than direct kindling of frontal cortex by first recruiting the PRh cortex.

A number of other experiments provide convincing evidence that the frontal cortex may be crucially involved in the generalization of discharge initiated in limbic structures. Corcoran et al. (1976) found that partial lesions of prefrontal or orbital corticies substantially increased the number of stimulations ordinarily required to kindle the amygdala. If the preferred pathway of seizure propagation did not involve the frontal cortex, a significant difference in limbic kindling should not have been found. McIntyre (unpublished results) provided further evidence that the frontal cortex may be critically involved in the amygdala's convulsive network when daily amygdala stimulation given three times longer than what would ordinarily be required could not evoke clonic seizures from animals with extensive bilateral lesions of the frontal cortex. Once again, if the frontal motor cortex was not involved in the generalization of limbic seizures, bilateral lesions of this area should not have prevented or significantly retarded amygdala kindling. Kelly et al., 1995 provided perhaps the most compelling evidence implicating the frontal cortex in amygdala-kindled seizures. They found that spreading depression induced by application of $\mathrm{KCl}$ into the frontal cortex ipsilateral or contralateral to a kindled amygdala blocked or lateralized amygdala kindled seizures respectively. Suppression of frontal cortex activity appears to have a large impact on limbic discharges triggered in the aniygdala that would normally be able to recruit motor mechanisms for convulsion generalization. 
The ability of the anterior deep layers to access motor structures faster than any other PRh area suggests that it may be the part of the PRh cortex most critically involved in the limbic convulsive network. Based on the progressive increase in the intensities necessary to trigger $S B$ and $A D$ thresholds from anterior to posterior PRh cortex, it is possible that the anterior deep layers possess the strongest connections to motor mechanisms involved in limbic seizure generalization and/or have the greatest intrinsic excitability. Since layer $V$ of the anterior PRh cortex is highly excitable in both the slice preparation (Battye, unpublished results) and whole animal (low threshold found in this thesis), and massively innervates frontal cortex cells that directly innervates the spinal cord, (Mclntyre et al., 1996), it is not surprising that this area can rapidly recruit networks involved in sustain motor convulsions.

\section{Final Thresholds}

$A D$ thresholds The dramatic decrease in $A D$ thresholds from initial to final threshold trials in all animals indicated a greater sensitivity of this responses to electrical stimulation following kindling. The most notable decrease in the intensity necessary to trigger an AD occurred posteriorly in group 4. Unlike the excessively high initial AD thresholds found from animals with electrodes placed in this group, the stimulus intensities needed to evoke an $A D$ on the final stimulation trial were similar to the thresholds found in the other PRh groups. However, although all PRh areas responded to lower intensities of electrical stimusation following kindling, a significant difference in final AD thresholds still existed between the superficial and the deep layers of the PRh cortex. Regardiess of prior kindling experience, the deep PRh lamina remained the most sensitive to electrical stimulation. It appears that this area consistently 
demonstrates highly excitable response properties both in the slice preparation and in the whole animal.

SB thresholds Compared to the initial SB thresholds, most PRh areas responded to lower intensities of stimulation with SB behaviors ranging anywhere from stage 1 to stage 4 following kindling. Since forelimb clonus is one of the major motor components involved in sustained seizure generalization, PRh areas that can most easily demonstrate this kind of motor behavior may be critically involved in limbic generalized convulsions. Except for the superficial and deep layers of group 4, all PRh regions demonstrated SB forelimb clonus during the final threshold trial. However, SB forelimb clonus was most readily triggered from the deep lamina of the two anterior PRh groups.

The many individual motor components observed during the kindling process may reflect the activation of different motor structures. Animals kindled from a number of limbic sites often demonstrate stage 1 and 2 motor behaviors such as chewing and head bobbing before stage 3 forelimb clonus. In addition to stage 1 and 2 motor behaviors, generalized motor responses from stages 3 to 5 may involve a number of individual motor components; including forelimb clonus, rearing, tail circling, and neck extensions. Kelly (1995) proposed that the forelimb clonus component of a limbic kindled seizure may be the result of frontal cortex activation through PRh projections, whereas the other aspects of a motor seizure may utilize independent pathways. Since the SB motor behaviors triggered from the PRh cortex during the two-second stimulation period and kindled motor behaviors are similar, perhaps they are activating the same motor structures. Although all layers of the PRh cortex project to the frontal cortex, layer $V$ may have facile access presumably through its massive periminofrontal connections. 
If frontal cortex activation is critically involved in the forelimb clonus component of a generalized convulsion, it is not surprising that this kind of SB motor response was easily elicited from most deep PRh regions. All animals with electrode placement in the deep layers of the two anterior groups demonstrated SB behaviors that progressed from stage 1-2 at lower intensities to forelimb clonus at higher intensities before an AD was triggered on the initial threshold trial. Unlike any other PRh area, forelimb clonus was evoked as the first observable SB behavior during the final threshold trial from the deep lamina of groups 1 and 2. Therefore, kindling appeared to potentiate anterior layer $V$ periminofrontal connections so that electrical stimulation subsequently provokes forelimb clonus not only as the first observable SB behavior, but at stimulus intensities lower than what would be required to trigger SB responses in any other PRh region.

Whereas SB forelimb clonus was almost always triggered from the deep lamina of groups 1 and 2, only half of the animals with electrode placements in the deep layers of group 3 demonstrated clonic motor SB responses during both the initial and final threshold trials. Although the thresholds for evoking final SB behaviors were similar for the deep layers of groups 1,2, and 3, the first sign of stimulus bound behavior in the deep layers of group 3, whether forelimb clonus was ever triggered or not, was stage 1-2 behavior. It appears that forelimb clonus was elicited in more animals and at lower thresholds in the deep lamina of the two anterior PRh groups compared to the deep layers of group 3. As the electrode placements moved everı more posterior to the deep regions of group 4, we were unable to trigger forelimb clonus on either the initial or final threshold trial. Only partial motor behavior could be evoked from this area during the two-second stimulation periods. As mentioned above, it was from the anterior deep regions that stimulation could most easily trigger SB 
forelimb clonus. It appears that although SB stage 1-2 motor responses could be triggered from all animals with electrodes in the deep PRh regions on either the initial or final threshold trial, the ability to trigger clonic SB responses became progressively more difficult as the stimulation locations moved from anterior to posterior within the deep PRh layers.

In general, the superficial layers presented a progressively stronger resistance to stimulus-triggered forelimb clonus from anterior to posterior PRh regions as well. All animals with electrode placements in the superficial layers of groups 1 and 2 demonstrated partial seizure behavior as their SB responses at lower stimulus intensities and SB forelimb clonus at higher intensities before an $A D$ was triggered. Although $S B$ motor behaviors could not be triggered during the initial threshold trial from the superficial lamina of group 3, we were able to evoke a progression of SB responses from stage 1 to stage 4 within this area as the stimulus intensity increased during the final threshold trial. It appears that although superficial group 3 was originally resistant to developing motor responses to electrical stimulation before kindling, direct or indirect networks with motor structures were developed during daily stimulation so that subsequent electrical stimulation below $A D$ thresholds could drive motor responses in a stimulus-locked manner.

In contrast to the development of superficial group 3 final SB responses following kindling, repeated daily stimulation did not promote any kind of final SB behaviors from the superficial group 4 lamina. As mentioned above, the initial and final SB responses triggered from the deep layers of group 4 never progressed past stage $1-2$ to include forelimb clonus. It appears that the most caudal region of the PRh cortex is either highly inhibited, actively suppressing this area from driving structures involved in forelimb clonus, or it does not possess sufficient direct connections with motor areas involved in SB motor 
responses to easily recruit the appropriate clonic forelimb response. Even though repeated daily stimulation lowers the posterior PRh AD thresholds, this area cannot drive mechanisms involved in SB clonic motor behaviors regardless of prior kindling experience.

Although PhAL injections made by McIntyre et al. (1996) demonstrating massive layer $\mathrm{V}$ projections to the frontal corter were restricted to the very anterior PRh regions, frontal cortex retrograde tracer Flourogold injections labeled cells throughout the entire PRh layer V. However, the flourogold injections were not discrete enough to determine what layers of the frontal cortex projected to different PRh regions. It may be through the particular frontal cortex afferents from the anterior PRh cortex that the forelimb clonus component of limbic seizures is realized. Conversely, if posterior PRh layer $V$ cells do not terminate in the critical frontal motor cortex areas directly involved in forelimb clonus activation, stimulation of this area may not as readily provoke SB or sustained forelimb clonus. Most likely it is the area within the frontal cortex to which different PRh regions projects that determined how quickly and easily forelimb clonus can be driven by electrical stimulation.

The posterior PRh cortex may demonstrate a greater resistance to forelimb clonus development than the anterior PRh areas because of poor frontal cortex innervation of cells directly involved in this kind of motor behavior. Until discrete anterograde injections are made in the caudal PRh cortex, we will be unable to determine whether the anterior and posterior layer $V$ neurons of the PRh cortex projects to the same frontal cortical areas. If the superticial layers need to recruit layer $V$ PRh cells for convulsion generalization, the anatomical possibility that the posterior PRh area is not able to directly tap into the same networks as the anterior PRh cortex could explain the ease with which anterior superficial layers activate forelimb clonus compared to that 
demonstrated by the superficial posterior lamina. The lack of SB forelimb clonus and the longer latencies to the onset of forelimb clonus of caudal PRh areas may reflect this areas need to recruit the anterior PRh layers in order to activate the appropriate frontal cortical areas involved in sustained forelimb clonus. The caudal PRh regions have been shown to provide strong direct projections to the anterior PRh cortex (Burwell et al. 1995). Perhaps all PRh areas have to access the frontal cortical areas crucially involved in convulsive seizure generalization through multisynaptic connections with the deep layers of the anterior PRh cortex.

\section{General Discussion}

The previous discussion has been based mostly on the recent electrophysiological (McIntyre \& Plant 1989;1991; Battye \& Mclntyre. unpublished results), anatomical (Mcintyre et al., 1996) and whole animal (Mclntyre et al., 1993) work conducted on the PRh cortex. This structure is now gaining considerable interest in learning, memory, and epilepsy literature presumably because of its broad network of cortical and subcortical connections. Electrophysiologically, layer V of the PRh cortex demonstrated greater excitation than any other PRh lamina (Mclntyre \& Plant, 1989;1991). Anatomically, it was previously suggested that the PRh layer $V$ connections with the frontal cortex may be critically involved in epileptogenisis (Mcintyre et al., 1996). In this thesis, we found the deep layers of the rostral PRh cortex to demonstrate a number of unique characteristics in the whole animal implicating it as an area that could be most crucially involved in seizure generalization. This area is able to tap into motor networks involved in generalized seizures more rapidly and at lower threshold than any other PRh area. 
A number of recent studies have provided indirect evidence that the PRh cortex may be recruited and modified during limbic kindling. Since most limbic structures, such as the amygdala, piriform cortex or entorhinal cortex, posses direct or indirect projections to the PRh cortex (McDonald \& Jackson, 1987), it is possible that this area is commonly accessed during all limbic kindling. By infusing muscimol unilaterally into the PRh cortex, Gale and colleagues were able to block bilateral clonic seizures triggered from the ipsilateral deep prepiriform cortex (Halonen et al., 1994), an area that heavily innervates the anterior PRh cortex (Sahibzada et. al, 1991; Mclntyre et al., 1996). Their findings demonstrated the critical influence the PRh cortex had on convulsive discharges initiated from a limbic structure such as the prepiriform cortex.

In addition to the possible involvement of the PRh cortex in the generalization of seizures initiated in the prepiriform cortex, a number of studies provide evidence that this PRh area may also be recruited during amygdala kindling. When stimulating the amygdala in the slice preparation, Mclntyre \& Plant (1989; 1991) discovered burst responses in the adjacent PRh cortex. Not only could this response be found in in vitro preparations, but, in anaesthetized rats, burst discharges were found in the PRh rostral deep layers when the lateral nucleus of the amygdala was stimulated (Velasco \& Molina, 1988). Taken together, it appears that 'epileptic' burst responses may be triggered in the PRh cortex during amygdala kindling. Anatomically, the amygdala has been reported to send projections exclusively to the anterior region of the PRh cortex (Burwell et al, 1995; Krettek \& Price, 1974, 1977; Ottersen, 1982; McDonald \& Jackson, 1987; Vaudano et al., 1990; Romanski and LeDoux, 1993; McIntyre et al, 1996). It is these direct connections that may allow the local convulsive after-discharge response triggered by repeated amygdala 
stimulation to eventually recruit the rostral PRh cortex as part of the limbic convulsive network.

If the PRh cortex is critical to the evolution of limbic kindled seizures, perhaps the after-discharge triggered from each limbic structure recruits its particular target area within this cortex as part of the convulsive network. It is possible that the local circuitry and anatomical properties of the PRh area recruited by a limbic structure may at least partly determine its particular kindling rate. McIntyre \& Kelly (1993) found that the rate of dorsal hippocampal kindling may depend on the intrinsic properties of distant limbic structures. They demonstrated a correspondence between amygdala/piriform/PRh excitability and dorsal hippocampal kindling rates. Faster dorsal hippocampal kindling was attained in animals with higher amygdala/piriform/PRh area excitability. In general, these findings suggest that extrinsic influences may play a large role in determining a structures kindling rate. Based on the supposition that the PRh cortex is more critical to the evolution of limbic convulsions than the amygdala/piriform area, perhaps the intrinsic properties of the hippocampal target area within the PRh cortex determines the speed at which convulsive discharges evolve to excite networks involved in seizure generalization. Since the deep layers of the rostral PRh cortex seem to most readily access motor structures, limbic discharges that propagate to this particular area may develop sustained convulsions more rapidly than structures that initially recruit caudal PRh regions.

Anatomical connections to the PRh cortex of structures such as the amygdala and hippocampus provides evidence that target areas within this cortex may directly influence their respective kindling rates. In the rat, several amygdaloid nuclei are interconnected with the rostral PRh cortex (Burwell et al, 1995; Krettek \& Price, 1974, 1977; Ottersen, 1982; McDonald \& Jackson, 1987; 
Vaudano et al., 1990; Romanski and LeDoux, 1993; Mcintyre et al, 1996) whereas virtually no connections with the amygdaloid complex have been reported for the caudal PRh region (Burwell et al., 1995). If amygdala kindling recruits the PRh cortex, the inherent excitability of the rostral PRh areas may at least partly determine the relatively rapid amygdala kindling rate.

Both CA-1 hippocampus and subiculum projections to the deep layer $V$ neurons in the PRh cortex have been determined (Witter et al., 1989). Kelly (1995) suggests that discharges triggered from the hippocampus may propagate via these connections into the posterior PRh cortex as the final conduit to seizure generalization since caudal PRh damage was shown to disrupt the normal propagation of hippocampal discharges. If hippocampal discharges utilize the posterior PRh cortex as part of the limbic seizLire network. the resistance to electrical stimulation demonstrated by this area may contribute to the slow kindling profile of the hippocampus.

In the context of learning and memory, the broad reciprocal connections of the PRh cortex with cortical and subcortical structures suggests that this area may have a strong information integrating and distributing capacity. In the context of epilepsy, this same pivotal area may be crucially involved in the spread of convulsive discharges. The ability of the anterior PRh cortex to demonstrate short latency convulsions that quickly become well-sustained may reflect this areas capacity to propagate strong synchronized discharges to frontal cortical areas involved in seizure generalization. As mentioned in the introduction, there is a lack of agreement on areas of the brain to be resectioned in patients undergoing surgical therapy to control intractable epilepsy.

However, it is important to note that good therapeutic results occur whether the resection involves an amygdalectomy alone (Feindel \& Rasmussen, 1991) or removal of the anterior hippocampus alone (Goldring, et al., 1992). In both 
cases, a substantial portion of the PRh cortex is removed along with the amygdala or hippocampus (P. Gloor, personal communication; A. Olivier, personal communication, D. Spencer, personal communication). Thus, this thesis provides further support for the view that the PRh cortex may be pivotal in the maintenance and/or propagation of convulsive limbic seizures. 


\section{References}

Aggleton, J.P., Hunt, P.R., \& Rawlins, J.N.P., The effects of hippocampal lesions upon spatial and non-spatial test of working memory. Behavioral Brian Research, 19 (1986) 133-146.

Awad, I.A., Katz, A., Hahn, J.R., Kong, A.K, Anl, J., \& Luders, H., Extent of resection in temporal lobectomy for epilepsy: I Interobserver analysis and correlation with seizure outcome, Epilepsia, 30 (1989) 756-762.

Babb, T.L., \& Brown, W.J., Pathological findings in epilepsy. In J. Jr. Engel. (Ed.) Surgical Treatment of the Epilepsies, New York: Raven Press, (1987) pp. $511-540$.

Barry, E., \& Hauser, W.A., Status epilepticus: The interaction of epilepsy and acute brain disease, Neurology, 43 (1993) 1473-1478.

Beldhuis, H.J., Behavioral characteristics and neuronal mechanisms of amygdala kindling, Doctoral Dissertation., University of Groningen. The Netherlands, (1993).

Burke, P.J., \& Hablitz, J.J., Metabotropic glutamate receptor activation decreases epileptiform activity in rat neocortex. Neuroscience Letters, 174 (1994) 29-33.

Burnham, W.M. Cortical and limbic kindling: Similarities and differences. In K.E. Livingston and O. Hornykiewicz (Eds.), Limbic Mechanisms: The Continuing Evolution of the Limbic System Concept, New York: Plenum Press (1978) pp.507-519.

Burwell, R.D., Witter, M.P., \& Amaral, D.G., Perirhinal and postrhinal rortices of the rat: A review of the neuroanatomical literature and comparision with findings from the monkey brain, Hippocampus, 5 (1995) 390-408.

Cain, D.P., Seizure develcpment following repeated electrical stimulation of central olfactory structures, Annals of the New York Academy of Sciences, (1977) 200-216.

Cain, D.P., Corcoran, M.E., Desborough, K.A., \& McKitrick, D.J., Is the deep prepyriform cortex a crucial forebrain site for kindling? Neuroscience Abstract, 14 (1988) 1149.

Corcoran, M.E., Urstad, H., McCaughran, J.A., JR., \& Wada, J.A., Frontal lobe and kindling in the rat, In J.A. Wada (Ed.), Kindling, New York: Raven Press (1976) pp. 215-228.

Deacon, T.W., Eichenbaum, H., Rosenberg, P., \& Eckmann, K.W., Afferent connections of the perirhinal cortex in the rat, Journal of Comparative Neurology, 220 (1983) 168-190. 
Feindel, W., \& Rasmussen, T., Temporal lobectomy with amygdalectomy and minimal hippocampal resection: Revien of 100 cases, Canadian Journal of Neurological Sciences, 18 (1991) 603-605.

French, J.A., Williamson, P.D., Thadani, V.M., Darcey, T.M., Mattson, R.H., Spender, S.S., \& Spencer, D.D., Characteristics of medial temporal lobe epilepsy: I. Results of history and physical examination, Annals of Neurology, 34 (1993) 774-780.

Gastaut, H., Dictionary of Epilepsy. I. Definitions, World Health Organization, Geneva, (1975).

Gean, P.W., Shinnick-Gallagher, P., \& Anderson, A.C., Spontaneous epileptiform activity and alteration of GABA- and of NMDA-mediate neurotransmission in amygdala neurons kindled in vivo, Brain Research, 494 (1989) 177-181.

Gloor, P., Role of the amygdala in temporal lobe epilepsy. In J. P. Aggleton (Ed.). The Amygdala: Neurobiological Aspects of Emotion, Memory, and Mental Dysfunction, New York: Wiley-Liss, Inc. (1992) pp. 505-538.

Goddard, G.V., McIntyre, D.C., \& Leech, C.K., A permanent change in brain function resulting from daily electrical stimulation, Experimental Neurology, 25 (1969) 295-330.

Goldring, W., Edwards, I., Harding, G.W., \& Bernaido, K.L., Results of anterior temporal lobectomy that spares the amygdala in patients with complex partial seizures, Journal of Neurosurgery, 77 (1992) 185-193.

Hauser, W.A., \& Kurland, L.T., The epidemiology of epilepsy in Rochester, Minnesota, 1935 through 1967, Epilepsia, 16 (1975) 1-66.

Hoffman, W.H., \& Haberly, L.B., Epileptiform potentials in slices of piriform cortex from kindled rats originate in deep structures, Society for Neuroscience Abstract, 17 (1991) 511.

Horel, J.A., Fytko-Joiner, D.E., Voytko, M., \& Salsbury, K., The performance of visual tasks while segments of the inferotemporal cortex are suppressed by cold, Behavioral Brain Research, 23 (1987) 29-42.

Insauti, R., Amaral, D.G., \& Cowan, W.M., The entorhinal cortex of the monkey: II. Cortical afferents, Journal of Comparative Neurology, 264 (1987) 356395.

Kairiss, E.W., Racine, R.J., \& Smith, G.K., The development of the interictal spike during kindling in the rat, Brain Research, 322 (1984) 101-110. 
Kelly, M.E., An investigation into temporal lobe seizure networks: Role of the piriform and perirhinal corticies in hippocampal kindled motor seizures. Doctoral Dissertation, Carleton University, Ontario, 1995.

Kelly, M.E., Battye, R.A., \& McIntyre, D.C., Lateralization of amygdala kindled convulsions by unilateral cortical spreading depression, Society for Neuroscience Abstract, 21 (1995) 1971.

Kesner, R.P., The role of the hippocampus within an attribute model of memory. Hippocampus, 1 (1991) 279-282.

Kosel, K.C., Van Hoesen, G.W.V., \& Rosene, D.L., Non-hippocampal cortical projections from the entorhinal cortex in the rat and mesus monkey. Brain Research, 244 (1982) 201-213.

Kosel, K.C., Van Hoesen,. B.W., \& Rosene, D.L., A direct projection from the periminal cortex (area 35) to the subiculum in the rat, Brain Research, 269 (1983) 347-351.

Krettek, J.E.. \& Price, J.L., Projections from the amygdala to the perirhinal and entorhinal corticies and the subiculum, Brain Research, 71 (1974) 150154.

Krettek, J.E., \& Price, J.L., Projections from the amygdaloid commplex to the cerebral cortex and thalamus in the rat and cat, Joumal of Comparative Neurology, 172 (1977) 687-722.

McCaughran, J.A., Corcoran, M.E., \& Wada, J.A., Role of the forebrain commissures in amygdaloid kindling in rats, Epilepsia, 19 (1978) 19-'33.

McDonald, A.J., \& Jackson, T.R., Amygdaloid connections with posterior insular and temporal cortical areas in the rat, Journal of Comparative Neurology. 262 (1987) 59-77.

McIntyre, D.C., \& Edson, N., Facilitation of secondary site kindling in the dorsal hippocampus following forebrain bisection, E),-rimental Neurology, 96 (1987) 569-579.

McIntyre, D.C., \& Goddard, G.V., Transfer, interference and spontaneous recovery of convulsions kindled from the rat amygdala, Electroencephalography and Clinical Neurophysiology, 35 (1973) 533543.

McIntyre, D.C., \& Kelly, M.E., Is the piriform cortex important for limbic kindling? In: J.A. Wada (ed.) Kindling 4, Plenum Press, New York, (1990) pp.21-29.

McIntyre, D.C. \& Kelly M.E., Pyriform cortex involvement in limbic kindling, Society for Nouroscience Abstract, 16 (1990) 1107 
McIntyre, D.C., \& Kelly, M.E., Are differences in dorsal hippocampal kindling related to amygdala-pirfiorm area excitability?. Epilepsy Research, 14 (1993) 49-61.

McIntyre, D.C., Kelly, M.E , \& Armstrong, J.N., Kindling in the perirhinal cortex, Brain Research, 615 (1993) 1-6.

McIntyre, D.C., Kelly, M.E., \& Staines, W.A., Efferent projections of the anterior perirhinal cortex in the rat, The Journal of Comparative Neurology, 369 (1996) 302-318.

McIntyre, D.C., Nathanson, D., \& Edson, N., A new model or partial status epilepticus based on kindling, Brain Research, 250 (1982) 53-63.

Mcintyre, D.C., \& Plant, J.R., Pyriform cortex involvement in kindling, Neuroscience \& Biobehavioral Reviews, 13 (1989) 277-280.

Mcintyre, D.C., \& Plant, J.R., Alteration of in vitro excitability after kindling. In F. Morrell (Ed.), Kindling and Synaptic Plasticity: The Legacy of Graham Goddard, Birkhauser, Boston, (1991) pp. 239-251.

Mcintyre, D.C., \& Racine, R.J., Kindling mechanisms: Current progress on an experimental epilepsy model, Progress in Neurobiology, 27 (1976) 1-12.

Mcintyre, D.C., \& Wong, R.K.S., Cellular and synaptic properties of amygdalakindled pyriform cortex in vitro, Journal of Neurophysiology, 55 (1986) 1295-1307.

Meunier, M., Murray, E.A., Bachevalier, J., \& Mishkin, M., Effects of perininal cortical lesions on visual recognition memory in hesus monkeys, Society for Neuroscience Abstracts, 16 (1990) 616.

Mishkin, M., Memory in monkeys severely impaired by combined but not by separate removal of amygdala and hippocampus, Nature, 273 (1978) 297 298.

Mumby, D.G., \& Pinel, J.P., Rhinal cortex lesions and object recognition in rats, Behavioral Neuroscience, 108 (1994) 11-18.

Mumby, D.G., Wood, E.R., \& Pinel, J.P.J., Object-recognition memory is only mildly impaired in rats with lesions of the hippocampus and amygdala, Psychobiology, 20 (1992) 18-27.

Murray, E.A., Bachevalier, J., \& Mishkin, M., Effects of thinal cortical lesions on visual recognition memory in rhesus monkeys, Society for Neuroscience Abstracts, 15 (1989) 342. 
Nayel, M.H., Awad, I.A., \& Luders, H., Extent of mesiobasal resection determines outcome after temporal lobectomy for intractable complex partial seizures, Neurosurgery, 29 (1991)55-61.

Otterson, O.P., Connections of the amygdala of the rat. IV: Corticoamygdaloid and intraamygdaloid connections as studies with axonal transport of horseradish peroxidase, Journal of Comparative Neurology, 205 (1982) 30-48.

Racine, R.J., Modification of seizure activity by electrical stimulation. I: Afterdischarge threshold, Electroencephalography \& Clinical Neurophysiology, 32 (1972a) 269-279.

Racine, R.j., Modification of seizure activity by electrical stimulation. II: Motor seizure, Electroencephalography \& Clinical Neurophysiology, 32 (1972b) 281-294.

Racine, R.J., Burnham, W.M., Gilber, M.., \& Kairiss, E.W., Kindling mechanisms: I. Electrophysiological studies. In J.A. Wada (Ed.), Kindling 3, Raven Press: New York, (1986) pp. 263-282.

Racine, R.J., Mosher, M., \& Kairiss, E.W., The role of the pyriform cortex in the generation of interictal spikes in the kirdled preparation, Brain Research, 454 (1988) 251-263.

Rannie, D.G., Asprodini, E.K., \& Shinnick-Gallagher, P., Kindling-induced longlasting changes in synaptic transmission in the basolateral amygdala. Journal of Neurophysiology, 67 (1992) 443-454.

Reep, R.L., \& S.S. Winans, Afferent connections of dorsal and ventral agranular insular cortex in the hamster Mesocricetus auratus, Neuroscience. 7 (1982) 1265-1288.

Reep R.L., Corwin, J.V., Hashimoto, A., \& Watson, R.T., Efferent connections of the rostral portion of medial agranular cortex in rats, Brain Research Bulletin, 19 (1987) 203-221.

Romanski, L.M., \& LeDoux, J.E., Information cascade from primary auditory cortex to the amygdala: Corticocortical and corticoamygdaloid projections of temporal cortex in the rat, Cerebral Cortex, 3 (1993) 515-532.

Rothblat, L.S.A., \& Kromer, L.R., Object recognition memory in the rat: The role of the hippocampus, Behavioural Brain Research, 42 (1991) 25-32.

Russchen, F.T., \& Price, J.L., Amygdalostriatal projections in the rat, Topographical organization and fiber morphology shown using the lectin PHAL, Neuroscience Letters, 47 (1984) 15-22. 
Sahibzada, N., Chen, W., Halonen, T., \& Gale, K., Anatomical connections of the area tempestas in the rat, Society of Neuroscience Abstracts, 17 (1991) 509.

Sato, M., Racine, R.J., \& McIntyre, D.C., Kindling: Basic mechanisms and clinical validity, Electroencephalography and Clinical Neurophysiology, 76 (1990) 459-472.

Saunders, R.C., \& Rosene, D.L., A comparison of the efferents of the amygdala and the hippocampal formation in the rhesus monkey: 1. Convergence in the entorhinal, prorhinal and perirhinal corticies, Journal of Comparative Neurology, 271 (1988) 153-184.

Sesack, S.R., Deutch, A.Y., Roth, R.H., \& Bunney, B.S., Topographical organization of the efferent projections of the medial prefrontal cortex in the rat: An anterograde tract-tracing study with Phaseolus vulgaris leucoagglutinin, Joumal of Comparative Neurology, 290 (1989) 213-242.

Spencer, D.D., Spender, S.S., Mattson, R.H., Williamson, P.D., \& Novelly, N.A., Access to the posterior medial temporal lobe structures in the surgical treatment of temporal lobe epilepsy, Neurosurgery, 15 (1984) 667-671.

Sripanidkulchai, K., Sripanidkulchai, B., \& Wyss, J.M., The cortical projection of the basolateral amygdaloid nucleus in the rat: $A$ retrograde fluorescent dye study, Joumal of Comparative Neurology, 229 (1984) 418-431.

Stefanacci, L., Farb, C.R., Pitkanen, A., Go, G., LeDoux, J.E., \& Amaral, D.G., Projections from the lateral nucleus to the basal nucleus of the amygdala: A light and electron microscopic PHA-L study in the rat, The Joumal of Comparative Neurology, 323 (1992) 586-601.

Suzuki, W.A., \& Amaral, D.G., Cortical inputs to the CA1 field of the monkey hippocampus originate from the perirhinal and parahippocampal cortex but not from area TE, Neuroscience Letters, 115 (1990) 43-48.

Suzuki, W.A., \& Amaral, D.G., Perithinal and parahippocampal corticies of the macaque monkey: Cortical afferents, Journal of Comparative Neurology, 350 (1994a) 497-533.

Suzuki, W.A., \& Amaral, D.G., Topographic organization of the reciprocal connections between the monkey entorhinal cortex and the perirhinal and parahippocampal corticies, The Journal of Neuroscience, 14 (1994b) 1856-1877.

Swanson, L.W., Brain Maps: Structure of the Rat Brain, Elsevier, Amsterdam (1992).

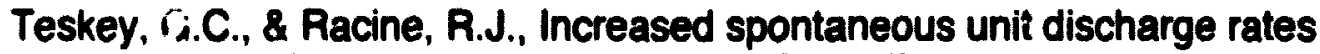
following electrical kindling in the rat, Brain Research, 624 (1993) 11-18. 
Turner, B.H., \& Zimmer, J., The architecture and some of the interconnections of the rat's amygdala and lateral periallocortex. The Journal of Comparative Neurology, 227 (1984) 540-557.

Van Hoesen, G.W., The parahippocampal gyrus. New observations regarding its cortical connections in the monkey. Trends in Neuroscience, 5 (1982) 345-350.

Vaudano, E., Legg, C.R., \& Glickstein, M., Afferent and efferent connections of temporal association cortex in the rat: a horseradish peroxidase study. European Journal of Neuroscience, 3 (1990) 317-330.

Velasco, J.M., \& De Molina, F., Unitary activity in the suprarhinal cortex of the rat and its modulation after lateral amygdala stimulation, Experimental Neurology, 99 (1988) 447-453.

Wada, J.A., Sato, M., \& Corcoran, M.E., Persistant susceptibility and recurrent spontaneous seizures in kindled cats, Epilepsia, 15 (1974) 465-478.

Wake, A., \& Wada, J.A., Frontal cortical kindling in cats. In J. Wada, (Ed.), Kindilng, New York: Raven Press. (1976) p.p. 203-214.

Watson, R.E., Troiano, R., Poulakos, J., Weiner, S., Block, D.H., \& Siegel, A., A

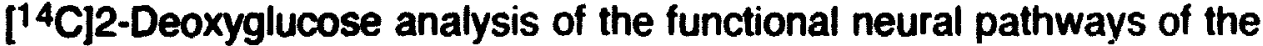
limbic forebrain in the rat. I. The Amygdala, Brain Research Reviews, 5 (1983) 1-44.

Wiig, K.A., \& Bilkey, D.K., The effects of perirhinal cortical lesions on spatial reference memory in the rat, Behavioral Brain Research, 63 (1994) 101109.

Williamson, P.D., Weiser, H.G., \& Delgado-Escueta, A.V., Clinical characteristics of partial seizures, In J. Jr. Engel (Ed.), Surgical Treatment of the Epilepsies., New York: Raven Press (1987).

Witter, M.P., \& Groenewegen, H.J., Connections of the parahippocampal cortex in the cat. III. Cortical and thalamic efferents, Journal of Comparative Neurology, 252 (1986) 1-31.

Witter, M.P., Groenewegen, H.J., Lopes da Silva. F.H., \& Lohman, A.H.M., Functional organization of the extrinsic and intrinsic circuitry of the parahippocampal region, Progress in Neurobiology, 33 (1989) 161-254.

Yasui, Y., Breder, C.D., Saper,C.B., \& Cechetto, D.F., Autonomic responses and efferent pathways from the insular cortex in the rat, Journal of Comparative Neurology, 303 (1991) 355-375. 
Zilles, K., Anatomy and the neocortex: Cytoarchitecture and myeloarchitecture. In B. Kolb and R.C. Tees (Eds), The Cerebral Cortex of the Rat, Cambridge: The MIT Press (1990) pp.77-112.

Zola-Morgan, S., Squire, L.R., Amaral, D.G., \& Suzuki, W., Lesions of the perirhinal and parahippocampal cortex that spare the amygdala and the hippocampal formation produce severe memory impairment, Journal of Neuroscience, 9 (1989) 4335-4370. 

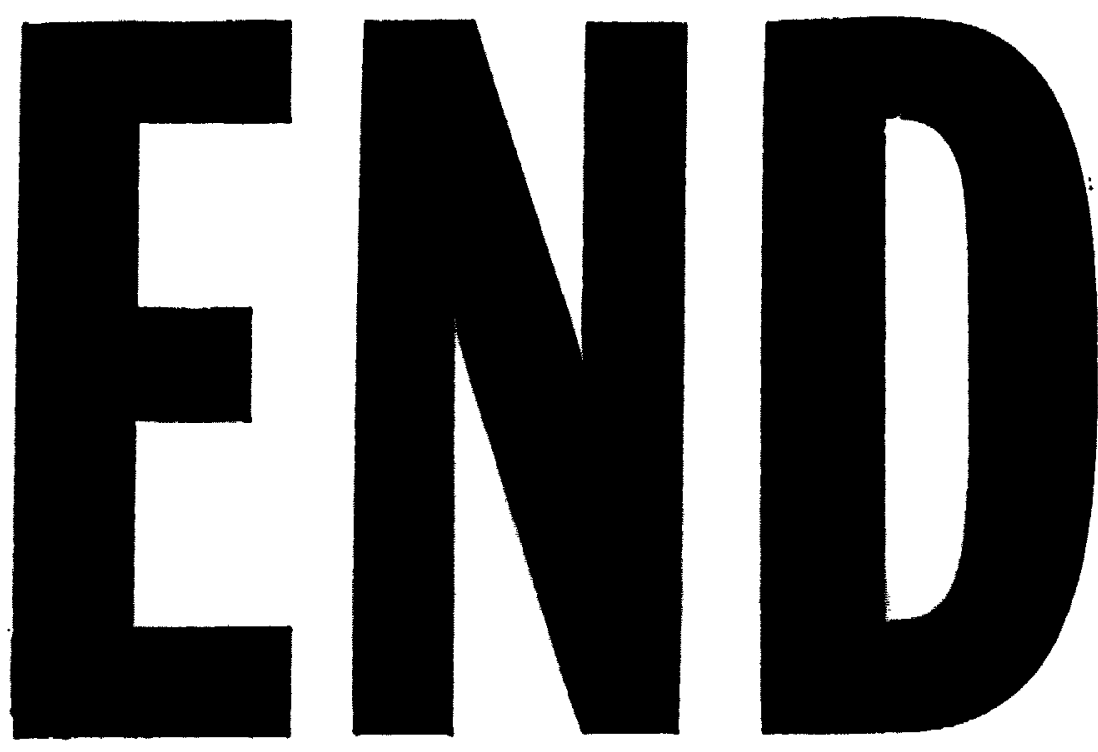

19.06 .97
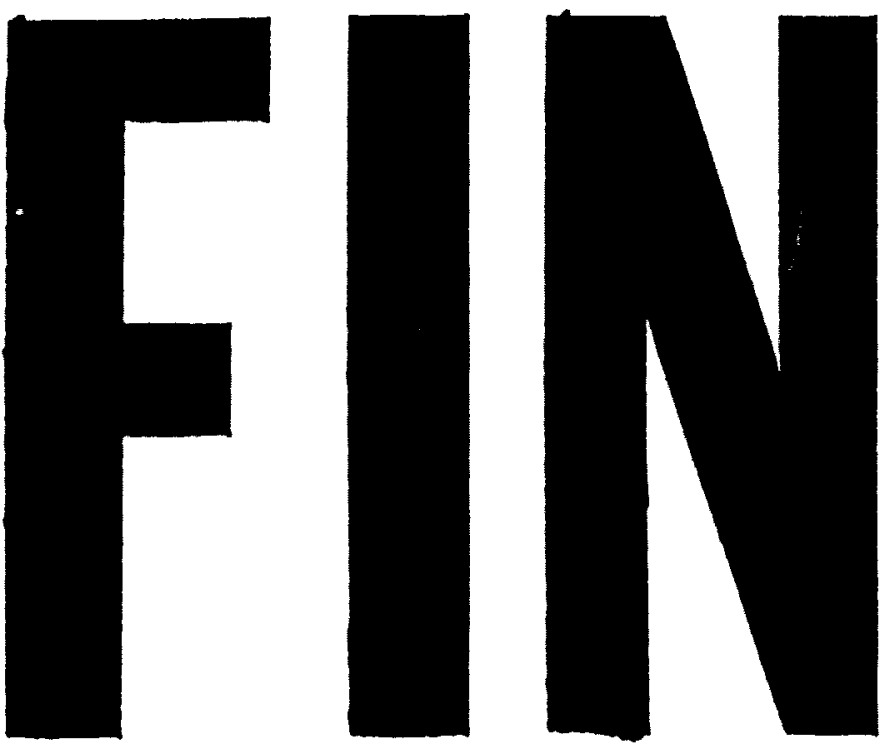